ARTICLE

https://doi.org/10.1038/s41467-021-27551-7

\title{
A $\mathrm{Mo}_{5} \mathrm{~N}_{6}$ electrocatalyst for efficient $\mathrm{Na}_{2} \mathrm{~S}$ electrodeposition in room-temperature sodium-sulfur batteries
}

Chao Ye $\mathrm{e}^{1,4}$, Huanyu Jin (10 1,4, Jieqiong Shan ${ }^{1,4}$, Yan Jiao (1) ${ }^{1}$, Huan $\mathrm{Li}^{1}$, Qinfen Gu (1) ${ }^{2}$, Kenneth Davey (1) ${ }^{1}$, Haihui Wang ${ }^{3 \otimes} \&$ Shi-Zhang Qiao (i) ${ }^{1 凶}$

Metal sulfides electrodeposition in sulfur cathodes mitigates the shuttle effect of polysulfides to achieve high Coulombic efficiency in secondary metal-sulfur batteries. However, fundamental understanding of metal sulfides electrodeposition and kinetics mechanism remains limited. Here using room-temperature sodium-sulfur cells as a model system, we report a $\mathrm{Mo}_{5} \mathrm{~N}_{6}$ cathode material that enables efficient $\mathrm{Na}_{2} \mathrm{~S}$ electrodeposition to achieve an initial discharge capacity of $512 \mathrm{mAh} \mathrm{g}^{-1}$ at a specific current of $1675 \mathrm{~mA} \mathrm{~g}^{-1}$, and a final discharge capacity of $186 \mathrm{mAh} \mathrm{g}^{-1}$ after 10,000 cycles. Combined analyses from synchrotron-based spectroscopic characterizations, electrochemical kinetics measurements and density functional theory computations confirm that the high $d$-band position results in a low $\mathrm{Na}_{2} \mathrm{~S}_{2}$ dissociation free energy for $\mathrm{Mo}_{5} \mathrm{~N}_{6}$. This promotes $\mathrm{Na}_{2} \mathrm{~S}$ electrodeposition, and thereby favours long-term cell cycling performance.

\footnotetext{
${ }^{1}$ School of Chemical Engineering \& Advanced Materials, The University of Adelaide, Adelaide, SA 5005, Australia. ${ }^{2}$ Australian Synchrotron (ANSTO), 800 Blackburn Rd, Clayton, VIC 3168, Australia. ${ }^{3}$ Beijing Key Laboratory of Membrane Materials and Engineering, Department of Chemical Engineering, Tsinghua University, 100084 Beijing, China. ${ }^{4}$ These authors contributed equally: Chao Ye, Huanyu Jin, Jiegiong Shan. $\varpi_{\text {email: cehhwang@tsinghua.edu.cn; }}$ s.qiao@adelaide.edu.au
} 
S ulfur is an attractive electrode material because of low cost and high-theoretical specific capacity of $\sim 1675 \mathrm{mAh} \mathrm{g}^{-11}$. Sulfur electrodes can be conjugated with a range of metal anodes in rechargeable metal-sulfur (M-S) batteries, giving promise of practical energy-storage applications ${ }^{2-4}$. However, sulfur reduction reaction (SRR) in $\mathrm{M}-\mathrm{S}$ batteries is a complex conversion from elemental sulfur to insoluble metal sulfides ${ }^{5}$. Sluggish SRR kinetics leads to incomplete conversion of the sulfur and "shuttle effect" of the polysulfides. This limits Coulombic efficiency (CE) and cycle-life and is therefore a deterrent to practical application 6 .

Metal sulfides electrodeposition from soluble polysulfides is the rate-determining step in practical sulfur electrodes ${ }^{7}$. Duan and co-workers demonstrated a slow conversion of soluble lithium polysulfides into insoluble lithium sulfides through studying the activation energy of various states of SRR in lithium-sulfur (Li-S) batteries $^{7}$. This leads to accumulation of lithium polysulfides in the electrolyte, and is the primary reason for the shuttle effect, together with a rapid capacity fading ${ }^{8}$. Despite electronically conductive materials with active electrodeposition sites, such as heteroatom-doped carbon, typically applied as substrates to facilitate charge transfer, an atomic-level understanding of mechanism of metal sulfides electrodeposition in SRR is lacking ${ }^{9-12}$. For example, although it is known that $\mathrm{Li}_{2} \mathrm{~S}$ electrodeposition is essential in $\mathrm{Li}-\mathrm{S}$ batteries, the solid-solid conversion from $\mathrm{Li}_{2} \mathrm{~S}_{2}$ to $\mathrm{Li}_{2} \mathrm{~S}$ is unclear because it is difficult to distinguish various solid products in the complex process ${ }^{13,14}$. Moreover, the correlation between the electrodeposition kinetics and geometric/electronic structure of the cathode materials remains unknown ${ }^{15-17}$. Consequently, there is significant research interest in how to realize highly efficient metal sulfides electrodeposition in $\mathrm{M}-\mathrm{S}$ batteries ${ }^{18}$.

Although SRR intermediates are too sensitive to be detected in air, advances in in-situ synchrotron characterizations with time resolution permit identification of specific polysulfides and metal sulfides and tracking of dynamic conversion ${ }^{19-21}$. In-depth understanding can therefore be achieved for macroscopic polysulfides conversion kinetics ${ }^{22,23}$. Nevertheless, atomic-level understanding of metal sulfides electrodeposition behavior is important and remains difficult to achieve experimentally ${ }^{24}$. Progress in density functional theory (DFT) computations that takes into account the geometric/electronic structure of the sulfur cathode materials is essential in investigating metal sulfides electrodeposition kinetics ${ }^{25}$. Therefore, combination of advanced in-situ synchrotron characterizations and computational quantum chemistry can reveal critical factors in metal sulfides electrodeposition kinetics ${ }^{26,27}$. Potential sulfur cathode materials with efficient metal sulfides electrodeposition kinetics can be engineered by tailoring geometric and electronic structures.

Here we present a $\mathrm{Mo}_{5} \mathrm{~N}_{6}$ cathode material that significantly catalyzes $\mathrm{Na}_{2} \mathrm{~S}$ electrodeposition and results in boosted performance for $\mathrm{Na}-\mathrm{S}$ battery: $512 \mathrm{mAh} \mathrm{g}^{-1}$ capacity and long cycle life of 10,000 cycles under $1 \mathrm{C}\left(1675 \mathrm{~mA} \mathrm{~g}^{-1}\right)$. Using a judicial combination of synchrotron-based characterizations, electrodeposition rate measurements and DFT computations, we evaluated the $\mathrm{Mo}_{5} \mathrm{~N}_{6}$ catalysts by linking extrinsic geometric structure with intrinsic reaction energetics in the $\mathrm{Na}_{2} \mathrm{~S}$ electrodeposition. With this research work we shed some light on the origin of high $\mathrm{Na}_{2} \mathrm{~S}$ electrodeposition reactivity and high SRR efficiency of this cathode material.

\section{Results}

Atomic and electronic structures of molybdenum nitrides. A series of molybdenum nitrides with varying atomic structure were selected as model cathode materials for investigation of correlation between the atomic structure, electronic structure and electrochemical performance in room-temperature sodium-sulfur (RT Na-S) batteries. $\mathrm{Mo}_{5} \mathrm{~N}_{6}, \mathrm{MoN}$, and $\mathrm{Mo}_{2} \mathrm{~N}$ with varying stoichiometries were synthesized based on reported synthetic strategies ${ }^{28}$. The crystal phases of the as-prepared molybdenum nitrides were analysed by powder X-ray diffraction (XRD), and indexed to crystalline $\mathrm{Mo}_{5} \mathrm{~N}_{6}, \mathrm{MoN}$, and $\mathrm{Mo}_{2} \mathrm{~N}$, respectively (Supplementary Fig. 1). The scanning electron microscopy (SEM) images of these molybdenum nitrides confirm that the $\mathrm{Mo}_{5} \mathrm{~N}_{6}$ and the MoN show a two-dimensional (2D) morphology and that $\mathrm{Mo}_{2} \mathrm{~N}$ exhibits a homogeneous nanoparticle morphology (Supplementary Fig. 2). In addition, high-angle annular dark-field scanning transmission-electron microscopy (HAADF-STEM) imaging was performed to investigate the atomic structure of the molybdenum nitrides (Supplementary Fig. 3). As is shown in Fig. 1a, the Mo atoms are labeled as redcolor spheres to aid visualization of the lattice fringes

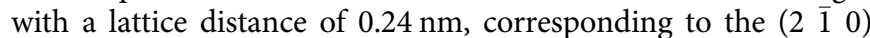
and ( $\left.\begin{array}{lll}1 & 1 & 0\end{array}\right)$ facets of the $\mathrm{Mo}_{5} \mathrm{~N}_{6}{ }^{28}$. In contrast, the MoN exhibits a lattice distance of $0.25 \mathrm{~nm}$ corresponding to the (200) and (2 $\overline{1} 0)$ facets. $\mathrm{Mo}_{2} \mathrm{~N}$ has two lattice distances of $0.24 \mathrm{~nm}$ and $0.21 \mathrm{~nm}$, which are ascribed to the $\left(\begin{array}{lll}2 & 0 & 0\end{array}\right)$ facet and (llll 111$)$ facet, respectively (Fig. 1b, c). This observation confirms the crystal structures of the molybdenum nitrides determined by XRD results and demonstrates the different Mo atomic configurations in the molybdenum nitrides.

It is reported that sulfur redox kinetics is significanty affected by the $d$ electron density of the materials, which regulates atomic structure $^{29}$. Mo $3 d$ X-ray photoelectron spectra (XPS) measurements showed that the $\mathrm{Mo}_{5} \mathrm{~N}_{6}$ has a higher dominant Mo valence state of $4+$ with a binding energy of $230.0 \mathrm{eV}$, in contrast, the $\mathrm{MoN}$ and $\mathrm{Mo}_{2} \mathrm{~N}$ exhibit lower binding energies of Mo species at 229.2 and $228.9 \mathrm{eV}$, respectively (Fig. 1d) ${ }^{30}$. This finding is supported by synchrotron-based near-edge X-ray absorption fine structure (NEXAFS) characterization that permits investigation of the impact on the surface electronic structures of the $d$ electrons. The Mo L-edge white-lines originate from $\mathrm{p}$ electron transition to a vacant $d$ electron state ${ }^{31}$. As is shown in the Mo- $\mathrm{L}_{3}, \mathrm{~L}_{2}$ edge NEXAFS spectra (Fig. 1e), the intensity of adsorption edge peak decreases in the order $\mathrm{Mo}_{5} \mathrm{~N}_{6}, \mathrm{MoN}$, and $\mathrm{Mo}_{2} \mathrm{~N}^{32}$. Therefore, the XPS and NEXAFS results demonstrate the high Mo valence state and low $d$ electron density of $\mathrm{Mo}_{5} \mathrm{~N}_{6}$ resulting from the unique atomic structure as is illustrated in Fig. 1f.

Electrochemical properties of the molybdenum nitrides in the RT Na-S batteries. To investigate electrocatalytic effects of molybdenum nitrides in RT Na-S batteries, we employed $\mathrm{Mo}_{\mathrm{x}} \mathrm{N}_{\mathrm{y}}$ catalysts as an additive and carbon-sulfur composite containing $62.9 \mathrm{wt} \%$ sulfur as active material in assembly of the sulfur electrodes. The as-prepared electrodes were denoted as $\mathrm{S} / \mathrm{Mo}_{5} \mathrm{~N}_{6}$, $\mathrm{S} / \mathrm{MoN}$, and $\mathrm{S} / \mathrm{Mo}_{2} \mathrm{~N}$ (Supplementary Fig. 4). For comparison, a pure S/C electrode was also prepared. Long-term cycling experiments at a high rate of $1 \mathrm{C}$ were conducted to investigate cycling performance of the sulfur electrodes (Fig. 2a and Supplementary Fig. 5). The capacity loss during initial few cycles was observed and is attributed to the formation of stable solid electrolyte interphase (SEI) film because of side effects between carbonated-based solvents and highly reactive sodium anode surface ${ }^{23,33}$. A high capacity of $186 \mathrm{mAh} \mathrm{g}^{-1}$ was maintained by the $\mathrm{S} / \mathrm{Mo}_{5} \mathrm{~N}_{6}$ after 10,000 continuous cycles under $1 \mathrm{C}$ that refers to an capacity decay of $0.0064 \%$ per cycle, together with a stabilized CE held at around $100 \%$. This performance significantly exceeds those of $\mathrm{S} / \mathrm{MoN}(0.014 \%)$ and $\mathrm{S} / \mathrm{Mo}_{2} \mathrm{~N}(0.024 \%)$. In contrast, the S/C electrode exhibited a low initial capacity of $201 \mathrm{~mA} \mathrm{~g}^{-1}$ with a short cycle life of less than 200 cycles 

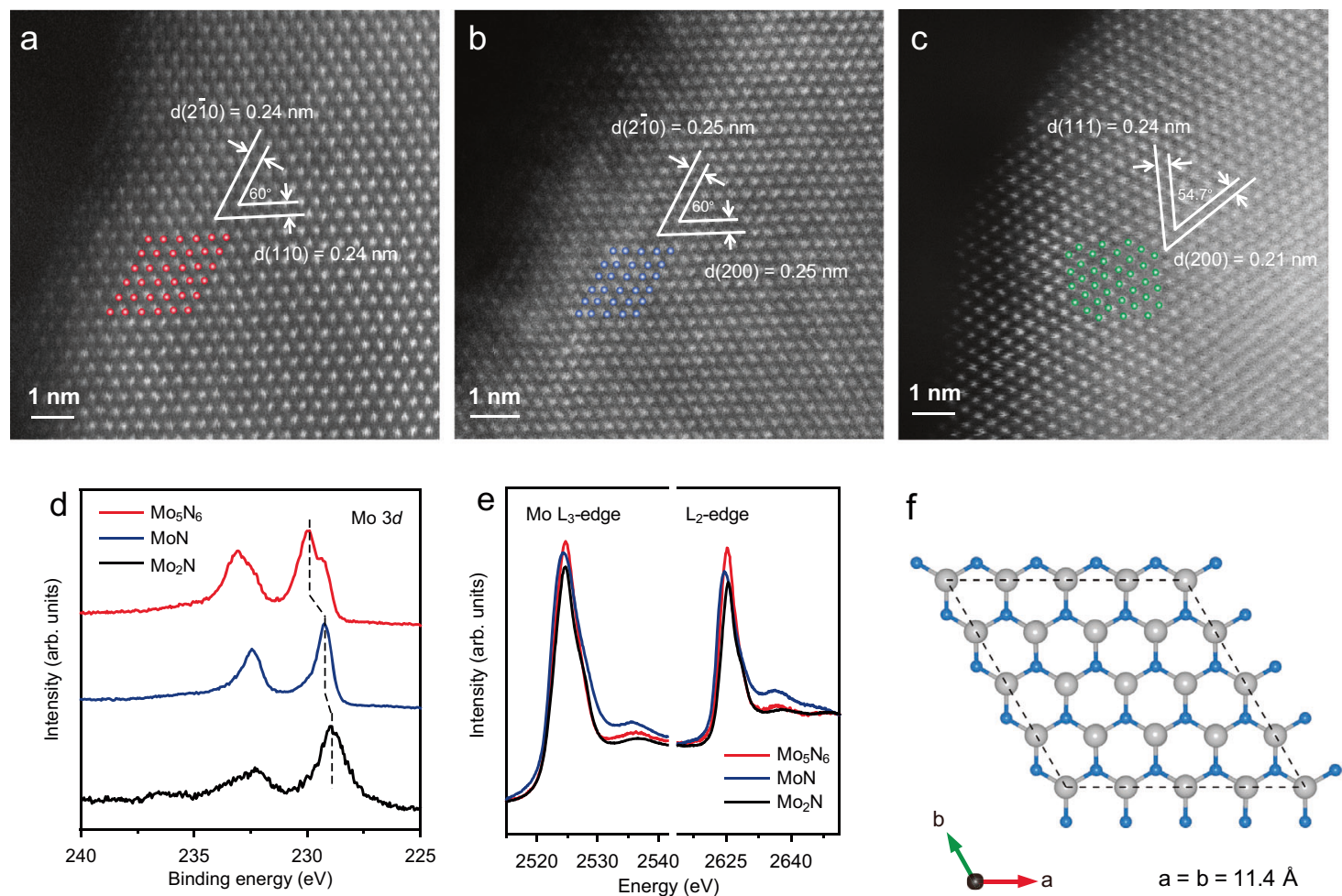

Fig. 1 Atomic and electronic structural characterization of $\mathbf{M o}_{5} \mathbf{N}_{6}, \mathbf{M o N}$ and $\mathbf{M o}_{\mathbf{2}} \mathbf{N}$. a-c HAADF-STEM images of $\mathrm{Mo}_{5} \mathrm{~N}_{6}, \mathrm{MoN}_{1}$ and $M 0_{2} \mathrm{~N}$. Insets are schematics of Mo configurations in which red-color, blue, and green spheres represent Mo atoms in $\mathrm{Mo}_{5} \mathrm{~N}_{6}, \mathrm{MoN}$ and $\mathrm{Mo}_{2} \mathrm{~N}$, respectively. d, e Mo $3 d$ XPS and $\mathrm{Mo} \mathrm{L}_{3}, \mathrm{~L}_{2}$-edge NEXAFS spectrum for $\mathrm{Mo}_{5} \mathrm{~N}_{6}, \mathrm{MoN}$, and $\mathrm{Mo}_{2} \mathrm{~N}$. f Computational model for $\mathrm{Mo}_{5} \mathrm{~N}_{6}(00$ 4). The gray and light-blue spheres represent Mo and $\mathrm{N}$ atoms, respectively.

(Supplementary Fig. 6). Therefore, the $\mathrm{S} / \mathrm{Mo}_{5} \mathrm{~N}_{6}$ electrode has practical promise for a high-performance $\mathrm{Na}-\mathrm{S}$ battery with high sulfur content, high capacity, small capacity decay and long cycling life in comparison with many reported sodium polysulfides cathodes, $\mathrm{Na}_{2} \mathrm{~S}$ cathodes, or hybrid of carbon and sulfur cathodes in Na-S batteries (Fig. 2b and Supplementary Fig. 7 and Supplementary Table 1) $)^{5,29,33-45}$. As is shown in Fig. $2 \mathrm{c}, \mathrm{S} / \mathrm{Mo}_{5} \mathrm{~N}_{6}$ exhibited a series of advantageous discharge capacities of 513, $353,304,263$, and $216 \mathrm{mAh} \mathrm{g}^{-1}$ when cycled at $0.1,0.2,0.5,1$, and $2 \mathrm{C}\left(1 \mathrm{C}=1675 \mathrm{~mA} \mathrm{~g}^{-1}\right)$, respectively. When the specific current was switched back to $0.2 \mathrm{C}$, a high discharge capacity of $325 \mathrm{mAh} \mathrm{g}^{-1}$ was maintained (Supplementary Fig. 8). Over the following cycling at $0.2 \mathrm{C}$ (Supplementary Figs. 9 and 10), the $\mathrm{S} / \mathrm{Mo}_{5} \mathrm{~N}_{6}$ exhibited a capacity decay of $0.013 \%$ per cycle (298-179 mAh g ${ }^{-1}$ in 2970 cycles). However, $\mathrm{S} / \mathrm{MoN}, \mathrm{S} / \mathrm{Mo}_{2} \mathrm{~N}$ and S/C cathodes show relatively poor cycling and rating performance with limited capacities under high rates (Supplementary Figs. 8-11).

To explore the origin of high CE and stability under high rates of the $\mathrm{S} / \mathrm{Mo}_{5} \mathrm{~N}_{6}$ cathode, we investigated the $\mathrm{Na}^{+}$diffusion of the three sulfur cathodes through cyclic voltammetry $(\mathrm{CV})$ experiments under various scan rates from 0.1 to $5 \mathrm{mV} \mathrm{s}^{-1}$ in the potential range $0.5-2.8 \mathrm{~V}^{46}$. During the initial cathodic scan (Supplementary Fig. 12) there was a prominent peak corresponding to reduction of elemental sulfur and long-chain soluble polysulfides to less soluble $\mathrm{Na}_{2} \mathrm{~S}_{2}$ and $\mathrm{Na}_{2} \mathrm{~S}$. For the anodic scan, one reproducible peak was observed. This corresponds to the oxidation of $\mathrm{Na}_{2} \mathrm{~S}_{2}$ and $\mathrm{Na}_{2} \mathrm{~S}$ to $\mathrm{Na}_{2} \mathrm{~S}_{\mathrm{x}}$ and elemental sulfur ${ }^{47}$. The slow oxidation kinetics of $\mathrm{Na}_{2} \mathrm{~S}_{2}$ and $\mathrm{Na}_{2} \mathrm{~S}$ to $\mathrm{Na}_{2} \mathrm{~S}_{\mathrm{x}}$ are likely the cause for the overlapping of the two oxidation peaks during the anodic scan. Based on the experimentally obtained slope between the peak current $\left(i_{\mathrm{p}}\right)$ and square root of the scan rate $\left(v^{1 / 2}\right)$, the diffusion coefficient for sodium ions was estimated from: $i_{\mathrm{p}} \propto n^{3 / 2} \mathrm{AD}^{1 / 2} c v^{1 / 2}$, where $i_{\mathrm{p}}, n, D, A, c$, and $v$ represent, respectively, peak current, number of electrons, diffusion coefficient, surface area of the electrode, concentration of the ion and voltage scanning rate (Fig. $2 \mathrm{~d})^{48}$. Because the number of electrons $(n)$ and concentration of the sodium ion $(c)$ are identical for the three sulfur electrodes, these cancel out in the $i_{\mathrm{p}}-v^{1 / 2}$ slope. Based on the electrochemical active surface areas (ECSAs) for the sulfur electrodes (Supplementary Fig. 13) the $i_{\mathrm{p}}-v^{1 / 2}$ slopes were normalized as is shown in Supplementary Fig. 14. It was confirmed that the $\mathrm{S} / \mathrm{Mo}_{5} \mathrm{~N}_{6}$ electrode exhibits greater sodium ion diffusion in comparison with that for $\mathrm{S} / \mathrm{MoN}$ and $\mathrm{S} / \mathrm{Mo}_{2} \mathrm{~N}$ electrodes. This likely causes deposition of a thick $\mathrm{Na}_{2} \mathrm{~S}$ layer on the electrode ${ }^{49,50}$.

To confirm the electrochemical measurements of diffusion rate, we computed the sodium ions diffusion barriers on the three molybdenum nitrides using climbing image nudged-elastic band (CI-NEB) method ${ }^{21}$. The three models were constructed based on the electron microscopy results, which are $\mathrm{Mo}_{5} \mathrm{~N}_{6}$ exposing $(00$ 4) facet, MoN with (l0 02 2) facet, and $\mathrm{Mo}_{2} \mathrm{~N}$ with (1 00 ) facet, as is shown in Supplementary Figure. $15^{51}$. The energy profiles for the ions diffusion on the three materials surface are shown in Fig. 2e, and the corresponding diffusion route in Supplementary Fig. 16. The diffusion barrier of sodium ions on the $\mathrm{Mo}_{5} \mathrm{~N}_{6}\left(\begin{array}{ll}0 & 0\end{array}\right)$ facet is $7 \mathrm{meV}$, which is significantly lower than those on the MoN $\left(\begin{array}{lll}0 & 0 & 2\end{array}\right)$ facet $(65 \mathrm{meV})$ and $\mathrm{Mo}_{2} \mathrm{~N}\left(\begin{array}{lll}1 & 0 & 0\end{array}\right)$ facet $(118 \mathrm{meV})$. Although the ( 004 ) facet for $\mathrm{Mo}_{5} \mathrm{~N}_{6}$ and $\left(\begin{array}{ll}0 & 0\end{array}\right)$ facet for $\mathrm{MoN}$ can be regarded as the only primary exposed facets because of inherent $2 \mathrm{D}$ morphology, we considered other possible facets of $\mathrm{Mo}_{2} \mathrm{~N}^{52,53}$. Given the 3D-morphology of $\mathrm{Mo}_{2} \mathrm{~N}$ an additional major exposed facet of $\left(\begin{array}{lll}1 & 1 & 1\end{array}\right)$ was investigated. This showed a significantly greater sodium ion barrier of $246 \mathrm{meV}$ over that for $\mathrm{Mo}_{2} \mathrm{~N}\left(\begin{array}{lll}1 & 0 & 0\end{array}\right)$ (Supplementary Figs. 17 and 18). Therefore, the computational results are consistent with the electrochemical results and confirm 

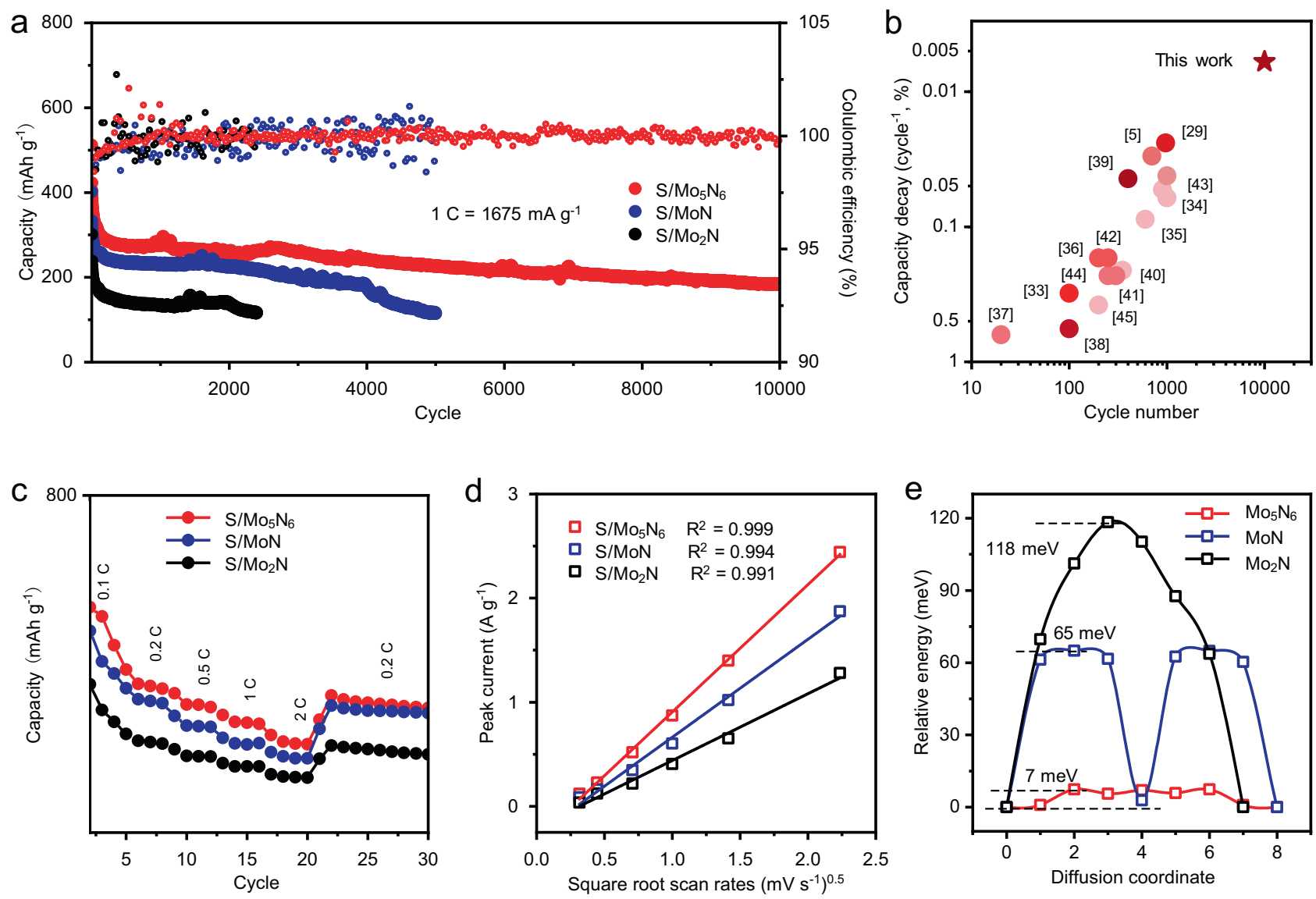

Fig. 2 Electrochemical properties of the molybdenum nitrides in RT Na-S batteries. a Cycling performance and CE for the three sulfur electrodes at $1 \mathrm{C}$. b Comparison of cycle number and capacity retention of recently reported RT Na-S cells with the present work, in which darker-color refers to greater specific current. c Rating capacities for $\mathrm{S} / \mathrm{Mo}_{5} \mathrm{~N}_{6}, \mathrm{~S} / \mathrm{MoN}$, and $\mathrm{S} / \mathrm{Mo}_{2} \mathrm{~N}$. $\mathbf{d}$ Linear relationship between peak current $\left(i_{\mathrm{p}}\right)$ and square root of scan rate $(v 1 / 2)$ for the three sulfur electrodes. e Energy profile for sodium ion diffusion on $\mathrm{Mo}_{5} \mathrm{~N}_{6}\left(\begin{array}{ll}0 & 0\end{array}\right)$ facet, $\mathrm{MoN}\left(\begin{array}{ll}0 & 0\end{array}\right)$ facet, and $\mathrm{Mo}_{2} \mathrm{~N}\left(\begin{array}{ll}1 & 0 \\ 0\end{array}\right)$ facet.

that the $\mathrm{S} / \mathrm{Mo}_{5} \mathrm{~N}_{6}$ electrode exhibits significantly greater sodium ion diffusion in comparison with the $\mathrm{S} / \mathrm{MoN}$ and $\mathrm{S} / \mathrm{Mo}_{2} \mathrm{~N}$ electrodes. These findings demonstrate that the $\mathrm{Mo}_{5} \mathrm{~N}_{6}$ represents an increased sodium ion diffusion rate and significantly promotes reaction kinetics between sodium and sulfur ${ }^{54}$.

Kinetic investigations on $\mathrm{Na}_{2} \mathrm{~S}$ electrodeposition. To determine the rate-determining step in overall SRR reaction, SRR kinetics were investigated on the $S / C$ electrode via determination of the energy barrier $\left(E_{\mathrm{a}}\right)$ with electrochemical impedance spectra (EIS) measurements and analysis 7 . The measured EIS curve was fitted with an equivalent circuit as is shown in Fig. 3a, in which $R_{\text {surf }}$ describes deposition of the adsorbed sodium polysulfides on the surface of the electrode, $R_{\mathrm{ct}}$ is the charge transfer process, and the "tail" is the Warburg resistance $\left(Z_{\mathrm{flw}} \text { and } Z_{\mathrm{fsw}}\right)^{55,56}$. The EIS curves for the $S / C$ electrodes under varying voltage were measured at temperatures of 303, 313, and $323 \mathrm{~K}$ (Supplementary Fig. 19). By fitting $R_{\mathrm{ct}}$ values in the Arrhenius equation, $E_{\mathrm{a}}$ at each voltage was evaluated (Supplementary Table 2). The conversion from $\mathrm{S}_{8}$ to $\mathrm{Na}_{2} \mathrm{~S}_{\mathrm{x}}(x=5-8)$ at 2.5 and $2.0 \mathrm{~V}$ results in low $E_{\mathrm{a}}$ values of 0.63 and $0.57 \mathrm{eV}$, whilst the conversion following to $\mathrm{Na}_{2} \mathrm{~S}_{4}$ and/or $\mathrm{Na}_{2} \mathrm{~S}_{3}$ at $1.5 \mathrm{~V}$ exhibits an increased $E_{\mathrm{a}}$ of $0.82 \mathrm{eV}$ (Fig. $3 \mathrm{~b}$ and Supplementary Table 3 ). During final conversion to $\mathrm{Na}_{2} \mathrm{~S}_{2} / \mathrm{Na}_{2} \mathrm{~S}$ in the voltage range 1.0 to $0.5 \mathrm{~V}, E_{\mathrm{a}}$ increases from 0.79 to $0.89 \mathrm{eV}$. These findings confirm that conversion of the $\mathrm{S}_{8}$ ring molecules to soluble $\mathrm{Na}_{2} \mathrm{~S}_{\mathrm{x}}$ is relatively facile, whereas the conversion of $\mathrm{Na}_{2} \mathrm{~S}_{4}$ and/or $\mathrm{Na}_{2} \mathrm{~S}_{3}$ to final insoluble $\mathrm{Na}_{2} \mathrm{~S}_{2} / \mathrm{Na}_{2} \mathrm{~S}$ is significantly more difficult, making it the rate-determining step for SRR. Similarly, EIS curves for S/ $\mathrm{Mo}_{5} \mathrm{~N}_{6}, \mathrm{~S} / \mathrm{MoN}$, and $\mathrm{S} / \mathrm{Mo}_{2} \mathrm{~N}$ electrodes were measured at a temperature of 303,313 , and $323 \mathrm{~K}$ (Supplementary Figs. 20-22). As is shown in Fig. 3c, d, $E_{\mathrm{a}}$ for S/ $\mathrm{Mo}_{5} \mathrm{~N}_{6}$ under each of $2.5,2.0$, and $1.5 \mathrm{~V}$, is, respectively, 0.53 , 0.57 , and $0.60 \mathrm{eV}$. These values are less than for $\mathrm{S} / \mathrm{MoN}$ of, respectively, $0.64,0.69$, and $0.79 \mathrm{eV}$ and for $\mathrm{S} / \mathrm{Mo}_{2} \mathrm{~N}$ of $0.67,0.71$, and $0.77 \mathrm{eV}$. Importantly, for the rate-determining step between 1.0 and $0.5 \mathrm{~V}, \mathrm{~S} / \mathrm{Mo}_{5} \mathrm{~N}_{6}$ exhibits significantly lower values of 0.73 and $0.74 \mathrm{eV}$ in comparison with those for $\mathrm{S} / \mathrm{MoN}$ of 0.78 and $0.80 \mathrm{eV}$, and for $\mathrm{S} / \mathrm{Mo}_{2} \mathrm{~N}$ of 0.80 and $0.84 \mathrm{eV}$. These findings evidence significantly boosted overall kinetics and $\mathrm{Na}_{2} \mathrm{~S}$ electrodeposition on $\mathrm{Mo}_{5} \mathrm{~N}_{6}$ compared with $\mathrm{MoN}$ and $\mathrm{Mo}_{2} \mathrm{~N}$.

To further investigate the $\mathrm{Na}_{2} \mathrm{~S}$ electrodeposition kinetics on $\mathrm{Mo}_{5} \mathrm{~N}_{6}$, in-situ synchrotron XRD measurements were conducted in transmission mode. A modified 2032-type coin cell with S/ $\mathrm{Mo}_{5} \mathrm{~N}_{6}$ as a cathode was discharged to $1.5 \mathrm{~V}$ (vs. $\mathrm{Na}^{+} / \mathrm{Na}$ ) using an in-house design to study the $\mathrm{Na}_{2} \mathrm{~S}$ electrodeposition, Fig. $4 \mathrm{a}$ (Supplementary Fig. 23) ${ }^{20}$. As can be seen from the figure in the discharge from $1.5 \mathrm{~V}$, two peaks at $12.8^{\circ}$ and $15.7^{\circ}$ are evident in the XRD patterns. These are assigned to soluble $\mathrm{Na}_{2} \mathrm{~S}_{5}$ (No. 00$027-0792)^{5,37}$. The other strong peak at $14.5^{\circ}$ corresponds to $\mathrm{Na}_{2} \mathrm{~S}_{4}$ (No. 04-003-2048). In addition, another peak at $11.9^{\circ}$ is assigned to the $\mathrm{Na}_{2} \mathrm{~S}_{3}$ (No. 00-044-0822) ${ }^{5}$. This finding reveals that the reduction of elemental sulfur to the mixture of sodium polysulfides occurs from open-circuit voltage to $1.5 \mathrm{~V}$ in discharge. This is consistent with the CV findings. When the battery was discharged to $\sim 1.0 \mathrm{~V}$, a peak at $13.6^{\circ}$ was observed. This is attributed to the (4 04 ) facet of $\mathrm{Na}_{2} \mathrm{~S}$ (No. 00-047-0178). 

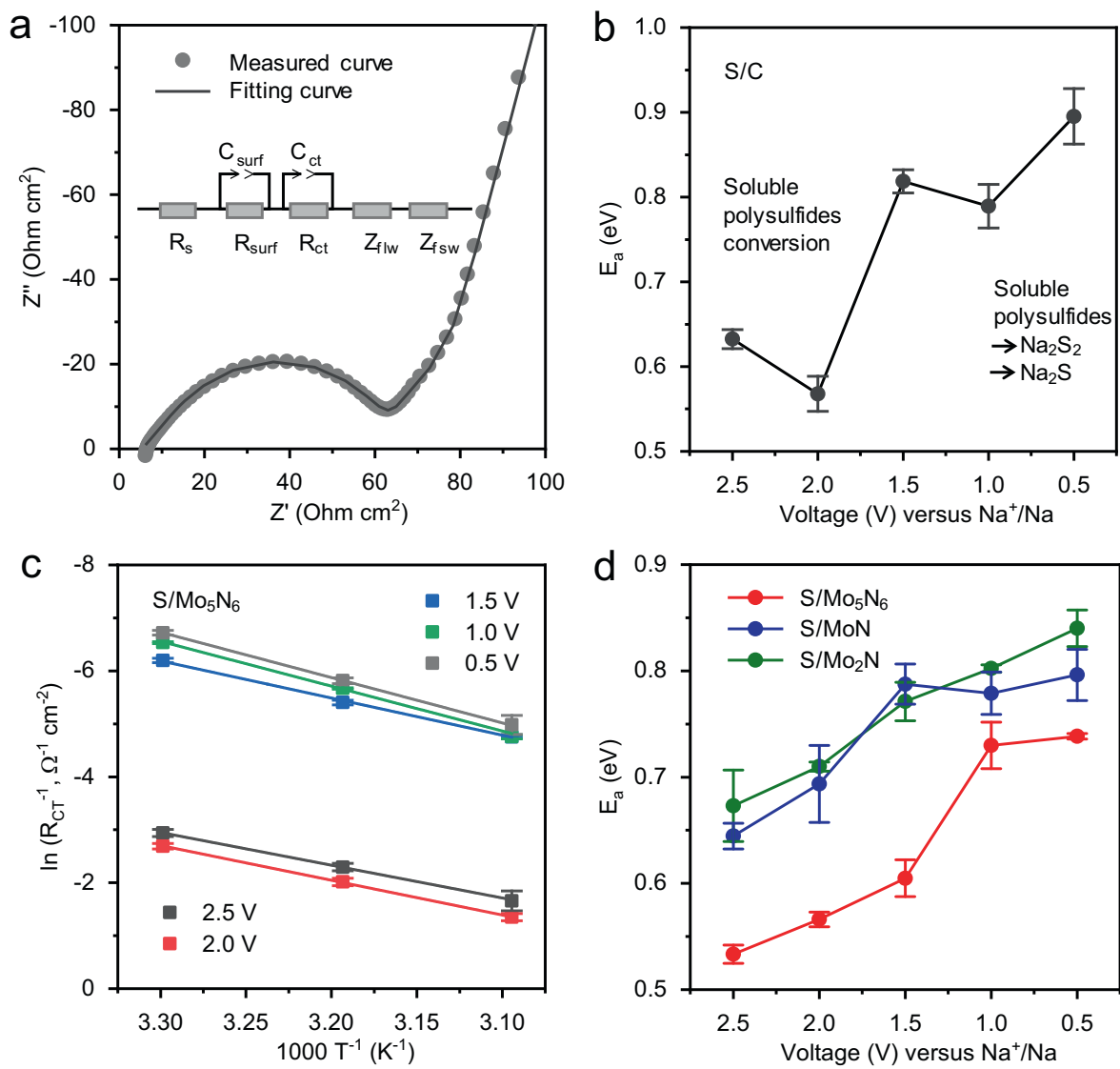

Fig. 3 Overall kinetics of sulfur reduction reaction in RT Na-S cells. a Measured and fitted curve for S/C electrode. The measured EIS curve can be fitted with an equivalent circuit as is shown in the inset, in which $R_{\text {surf }}$ describes deposition of adsorbed sodium polysulfides on the surface of the electrode, $R_{\mathrm{ct}}$ is attributed to the charge transfer process, and the tail line represents the Warburg resistance $\left(Z_{\mathrm{flw}}\right.$ and $\left.Z_{\mathrm{fsw}}\right)$ in the pure sulfur cathode. $\mathbf{b}$ Activation energy for $\mathrm{S} / \mathrm{C}$ electrode at varying voltage. The $E_{\mathrm{a}}$ study confirms that conversion of $\mathrm{Na}_{2} \mathrm{~S}_{4}$ and/or $\mathrm{Na}_{2} \mathrm{~S}_{3}$ to final insoluble $\mathrm{Na}_{2} \mathrm{~S}_{2} / \mathrm{Na}_{2} \mathrm{~S}$ is the rate-determining step for SRR. The errors originate from the linear fitting of Arrhenius plots for $R_{\mathrm{ct}}$. c Arrhenius-plots for $R_{\mathrm{ct}}$ for $\mathrm{S} / \mathrm{Mo}_{5} \mathrm{~N}_{6}$. Values for $R_{\mathrm{ct}}$ were obtained by fitting using an equivalent circuit as is shown in the inset of panel $\mathbf{a}$. The error bars represent relative errors of the fitted $R_{\mathrm{ct}}$ values. $\mathbf{d}$ Activation energy for the three sulfur electrodes at varying voltage. Errors originate from the linear fitting of Arrhenius plots for $R_{\mathrm{ct}}$.

In the further discharge to $\sim 0.8 \mathrm{~V}$, a peak located at $13.7^{\circ}$ is assigned to the $\left(\begin{array}{lll}1 & 0 & 2\end{array}\right)$ facet of $\mathrm{Na}_{2} \mathrm{~S}_{2}$ (No. 04-007-3813). In the discharge from 1.5 to $0.5 \mathrm{~V}$, most of the polysulfides in the battery were oxidized to $\mathrm{Na}_{2} \mathrm{~S}$. Importantly, the peak for $\mathrm{Na}_{2} \mathrm{~S}$ is seen before the appearance of the $\mathrm{Na}_{2} \mathrm{~S}_{2}$ phase. This finding contrasts with previous report that $\mathrm{Na}_{2} \mathrm{~S}_{2}$ was formed prior to $\mathrm{Na}_{2} \mathrm{~S}^{57}$. This unusual phenomenon leads to an assumption that $\mathrm{Mo}_{5} \mathrm{~N}_{6}$ exhibits very fast conversion kinetics from $\mathrm{Na}_{2} \mathrm{~S}_{2}$ to $\mathrm{Na}_{2} \mathrm{~S}$, that result in highly favorable $\mathrm{Na}_{2} \mathrm{~S}$ electrodeposition on the $\mathrm{S} / \mathrm{Mo}_{5} \mathrm{~N}_{6}$ cathode.

$\mathrm{Na}_{2} \mathrm{~S}$ electrodeposition rate experiments were carried out to investigate electrodeposition kinetics of the three cathode materials. The potentiostatic experiments were designed and modified based on the reported $\mathrm{Li}_{2} \mathrm{~S}$ electrodeposition experiments ${ }^{11,58,59}$. In order to distinguish the electrodeposition of $\mathrm{Na}_{2} \mathrm{~S}$ from the reduction of higher-order polysulfides $\left(\mathrm{Na}_{2} \mathrm{~S}_{5}\right)$ in solution, the cell was discharged galvanostatically to a potential of $1.0 \mathrm{~V}$ at a rate of $\mathrm{C} / 24$. Subsequently, the electrodeposition was carried out at a fixed potential of $0.5 \mathrm{~V}\left(\mathrm{vs} . \mathrm{Na} / \mathrm{Na}^{+}\right)$. We present the fitting results via colored areas to demonstrate the capacity contributions of the $\mathrm{Na}_{2} \mathrm{~S}$ electrodeposition in Fig. $4 \mathrm{~b}-\mathrm{d}$. The capacities of the $\mathrm{Na}_{2} \mathrm{~S}$ electrodeposition on carbon paper (CP)/ $\mathrm{Mo}_{5} \mathrm{~N}_{6}, \mathrm{CP} / \mathrm{MoN}$, and $\mathrm{CP} / \mathrm{Mo}_{2} \mathrm{~N}$ were determined to be 208.3 , 147.5 , and $104.9 \mathrm{mAh} \mathrm{g}^{-1}$ based on the sulfur mass, respectively. It is seen that $\mathrm{Mo}_{5} \mathrm{~N}_{6}$ exhibits significantly greater $\mathrm{Na}_{2} \mathrm{~S}$ electrodeposition capacity in comparison with that for MoN and $\mathrm{Mo}_{2} \mathrm{~N}$. In addition, the highest peak current of $0.80 \mathrm{~mA}$ was observed during the electrodeposition on the $\mathrm{Mo}_{5} \mathrm{~N}_{6}$ as shown in the insets of Fig. 4b-d. The electrodeposition morphology of the $\mathrm{Na}_{2} \mathrm{~S}$ on $\mathrm{CP} / \mathrm{Mo}_{5} \mathrm{~N}_{6}, \mathrm{CP} / \mathrm{MoN}, \mathrm{CP} / \mathrm{Mo}_{2} \mathrm{~N}$, and $\mathrm{CP}$ was investigated by SEM imaging and energy-dispersive spectroscopy (EDS) mapping analysis (Fig. 4e-g and Supplementary Figs. 24-27). It was found that $\mathrm{Na}_{2} \mathrm{~S}$ is uniformly deposited on the surface of $\mathrm{CP} /$ $\mathrm{Mo}_{5} \mathrm{~N}_{6}$ with approximately $100 \%$ coverage. A three-dimensional (3D) deposition of $\mathrm{Na}_{2} \mathrm{~S}$ layers on the $\mathrm{CP} / \mathrm{Mo}_{5} \mathrm{~N}_{6}$ highlights the high deposition efficiency ${ }^{60}$. This is attributed to the low energy barriers of $\mathrm{Na}_{2} \mathrm{~S}$ nucleation and growth on $\mathrm{Mo}_{5} \mathrm{~N}_{6}$. $\mathrm{CP} / \mathrm{MoN}, \mathrm{CP} /$ $\mathrm{Mo}_{2} \mathrm{~N}$, and $\mathrm{CP}$ exhibited an insufficient $\mathrm{Na}_{2} \mathrm{~S}$ deposition with discrete coating as was evidenced by low $\mathrm{Na}_{2} \mathrm{~S}$ coverage on the electrode surface (Supplementary Figs. 25-27). The sluggish $\mathrm{Na}_{2} \mathrm{~S}$ electrodeposition kinetics on $\mathrm{CP} / \mathrm{MoN}$ and $\mathrm{CP} / \mathrm{Mo}_{2} \mathrm{~N}$ are explained by the very high energy barriers for the redox reaction of polysulfides on them. The XPS spectra for the three sulfur electrodes discharged to $0.5 \mathrm{~V}$ were analyzed to confirm the electrochemical catalytic activity of $\mathrm{Mo}_{5} \mathrm{~N}_{6}$. It is seen in Supplementary Fig. 28 that the $\mathrm{S} / \mathrm{Mo}_{5} \mathrm{~N}_{6}$ cathode exhibits dominate $\mathrm{S}^{2-}$ species at the end of discharge, underscoring a highly efficient conversion of active sulfur species to $S^{2-61,62}$. In contrast, $\mathrm{S} / \mathrm{MoN}$ and $\mathrm{S} / \mathrm{Mo}_{2} \mathrm{~N}$ cathodes show only partial conversion to $\mathrm{S}^{2-}$. This finding is attributed to the strong adsorption of sodium polysulfides and low diffusion barrier of sodium ions. The EIS tests were conducted at $0.5 \mathrm{~V}$, and 

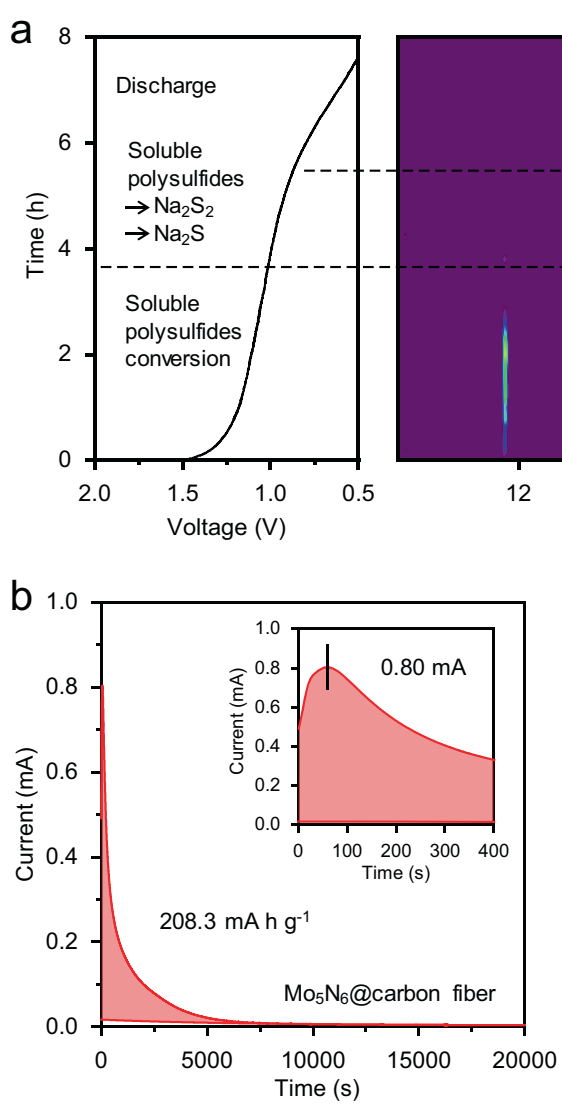

e

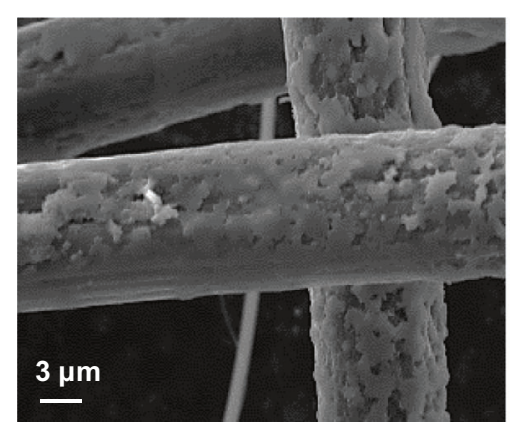

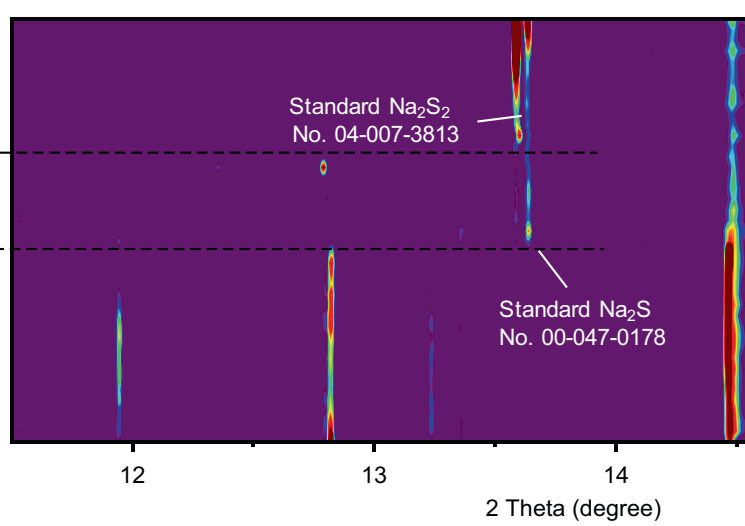
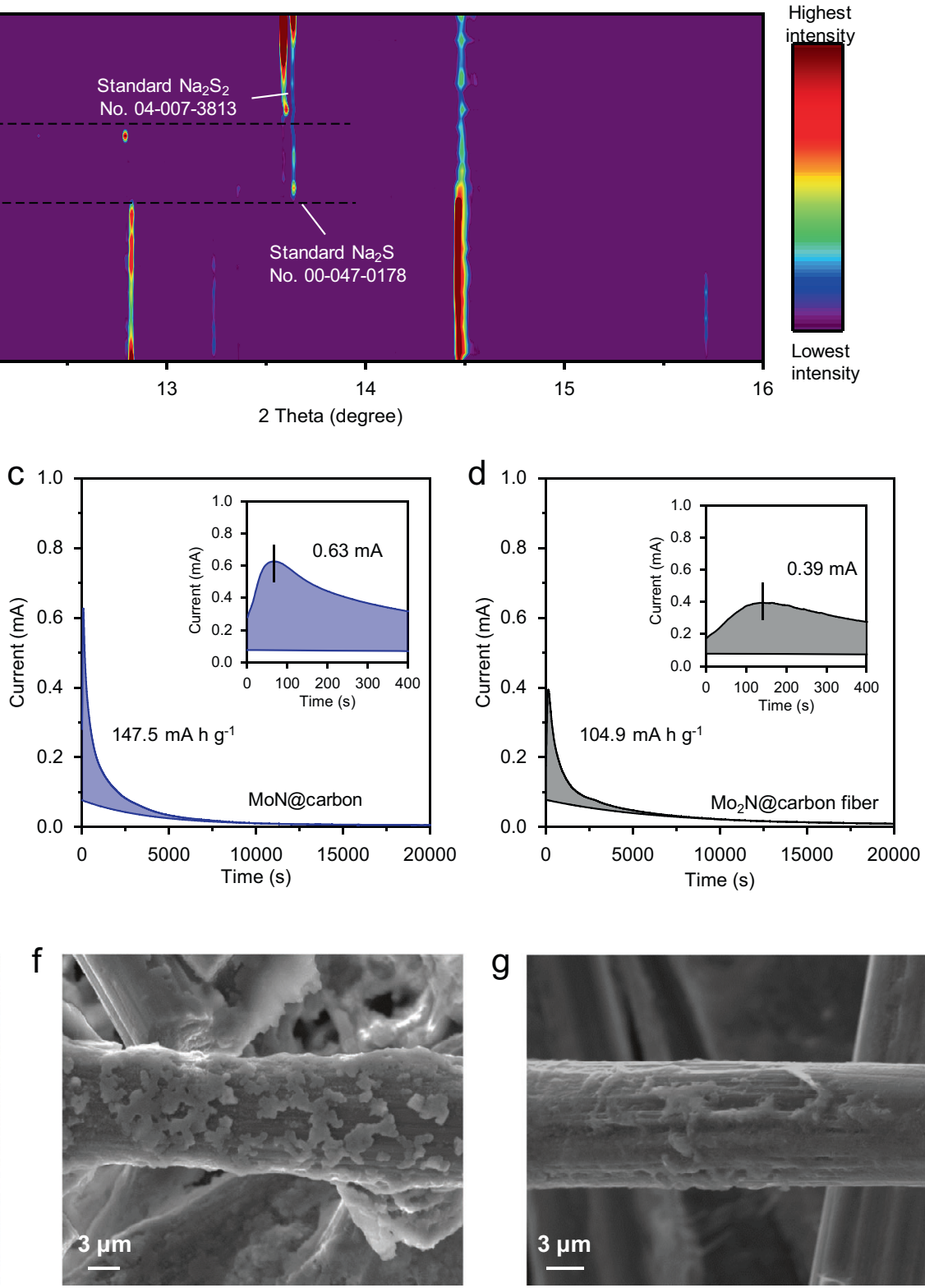

Fig. 4 Kinetic investigations of $\mathbf{N a}_{\mathbf{2}} \mathbf{S}$ electrodeposition. a Galvanostatic discharge curve and corresponding in-situ synchrotron XRD patterns for $\mathrm{S} /$ $\mathrm{Mo}_{5} \mathrm{~N}_{6}$ electrode. b-d Potentiostatic discharge curves for electrodeposition rate measurements on the three materials. Insets are the first $400 \mathrm{~s}$ in the electrodeposition. e-g SEM images of electrodeposition tests on the three cathode materials.

corresponding $R_{\text {surf }}$ values which describe the deposition of insoluble sodium polysulfides on the electrode surfaces, and fitted to be $\sim 485, \sim 281$, and $\sim 230 \Omega \mathrm{cm}^{2}$ for $\mathrm{S} / \mathrm{Mo}_{5} \mathrm{~N}_{6}, \mathrm{~S} / \mathrm{MoN}$, and S/ $\mathrm{Mo}_{2} \mathrm{~N}$ electrodes, respectively (Supplementary Fig. 29). This finding agrees well with those from the $\mathrm{Na}_{2} \mathrm{~S}$ electrodeposition test and the S 2p XPS analysis, confirming the highly efficient $\mathrm{Na}_{2} \mathrm{~S}$ electrodeposition on $\mathrm{Mo}_{5} \mathrm{~N}_{6}$ in comparison with the others ${ }^{41,63}$.

\section{Discussion}

To determine the origin of the significant deposition efficiency and cycling stability of $\mathrm{S} / \mathrm{Mo}_{5} \mathrm{~N}_{6}$, DFT computations on thermodynamics and kinetics of $\mathrm{Na}_{2} \mathrm{~S}$ electrodeposition on various molybdenum nitride surfaces were carried out. The adsorption configurations and adsorption energies for $\mathrm{Na}_{2} \mathrm{~S}_{\mathrm{n}}(n=1-5)$ on the three nitrides were investigated. As is shown in the adsorption configurations, Supplementary Figs. $30-32, \mathrm{~S}$ in $\mathrm{Na}_{2} \mathrm{~S}_{\mathrm{n}}$ locates in the hollow sites on $\mathrm{Mo}_{5} \mathrm{~N}_{6}$, whilst $\mathrm{Na}$ in $\mathrm{Na}_{2} \mathrm{~S}_{\mathrm{n}}$ locates away from the surface. This implies that Mo functions as a dominant adsorption site to interact with $\mathrm{S}$ in $\mathrm{Na}_{2} \mathrm{~S}_{\mathrm{n}}{ }^{64}$. The adsorption energies for $\mathrm{Na}_{2} \mathrm{~S}_{\mathrm{n}}$ on $\mathrm{Mo}_{5} \mathrm{~N}_{6}$ were, respectively, $-6.14,-8.75$, $-7.67,-6.36$, and $-9.23 \mathrm{eV}$ for $n=1,2,3,4$, and 5, Supplementary Fig. 33 (Supplementary Table 4). These high values confirm strong adsorption of $\mathrm{Na}_{2} \mathrm{~S}_{\mathrm{n}}$ on $\mathrm{Mo}_{5} \mathrm{~N}_{6}$ when compared with reported materials in sulfur cathodes for lithium/sodium polysulfides adsorption ${ }^{65}$. Although adsorption energies for $\mathrm{Na}_{2} \mathrm{~S}_{\mathrm{n}}$ on $\mathrm{Mo}_{5} \mathrm{~N}_{6}$ were (slightly) greater than those on MoN, it was not clear why there is faster deposition kinetics on $M_{0} \mathrm{~N}_{6}$ compared with MoN.

To determine the origin of the fast $\mathrm{Na}_{2} \mathrm{~S}$ electrodeposition kinetics on $\mathrm{Mo}_{5} \mathrm{~N}_{6}$, we constructed a three-step reaction pathway for $\mathrm{Na}_{2} \mathrm{~S}_{2}$ conversion to $\mathrm{Na}_{2} \mathrm{~S}$ on the three molybdenum nitrides surfaces. The corresponding reaction steps are: 1) adsorption of $\mathrm{Na}_{2} \mathrm{~S}_{2}, 2$ ) formation of adsorbed $\mathrm{Na}^{*}$ and $\mathrm{NaS}_{2}{ }^{*}$ from $\mathrm{Na}_{2} \mathrm{~S}_{2}$ 

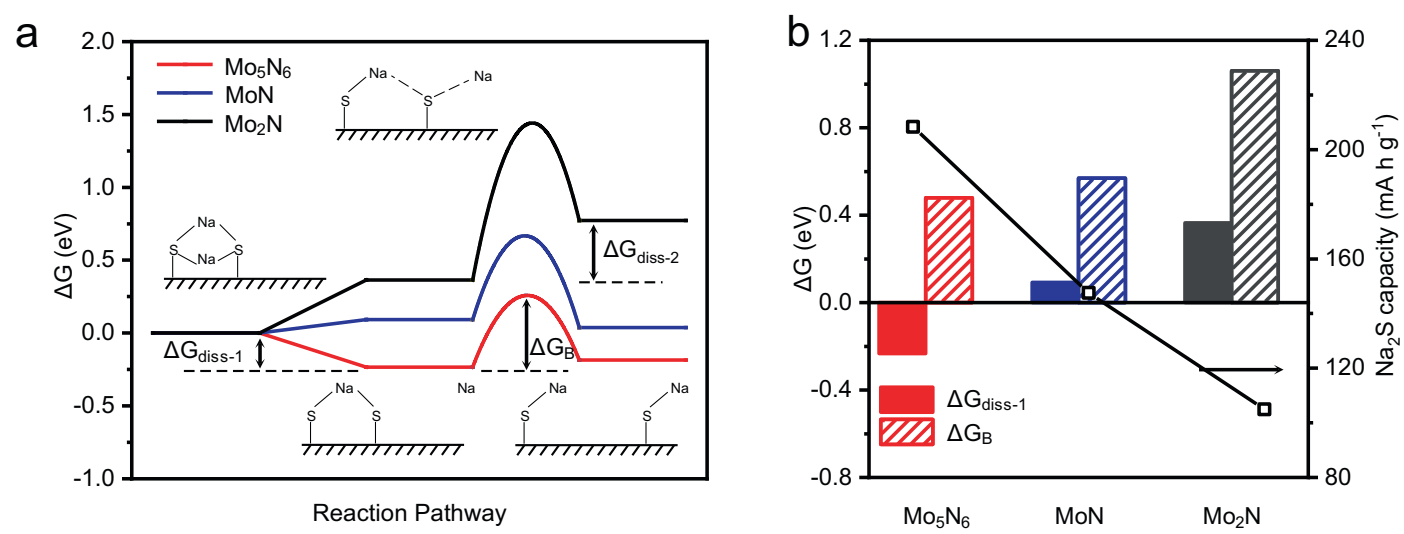

\section{C}

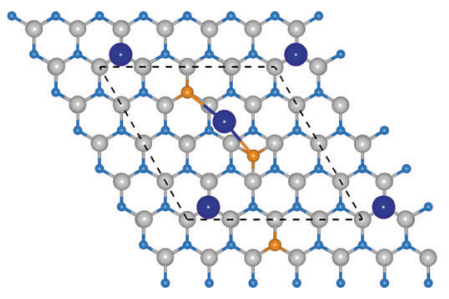

Initial state

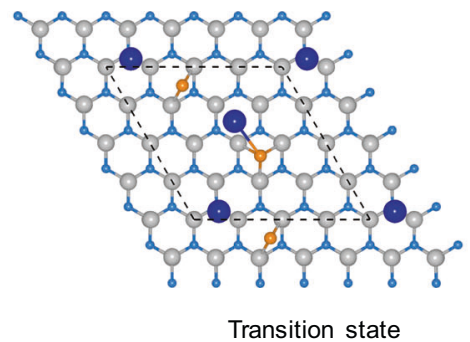

Transition state

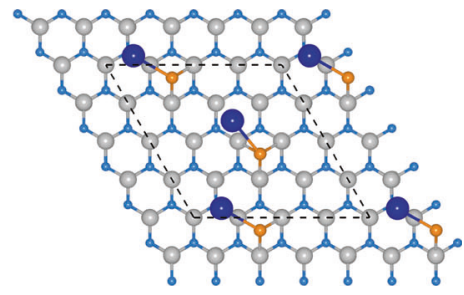

Final state

Fig. 5 Computational investigation of $\mathbf{N a}_{2} \mathbf{S}$ electrodeposition. a Gibbs free energy diagram of conversion from $\mathrm{Na}_{2} \mathrm{~S}_{2}$ to $\mathrm{NaS}^{\star}$ on the three surfaces including adsorption of $\mathrm{Na}_{2} \mathrm{~S}_{2}$, dissociation of $\mathrm{Na}_{2} \mathrm{~S}_{2}$ to form adsorbed $\mathrm{NaS}_{2}\left(\mathrm{NaS}_{2}{ }^{*}\right)$ and formation of adsorbed $\mathrm{NaS}\left(\mathrm{NaS}^{\star}\right)$ from the $\mathrm{NaS}_{2}{ }^{*} . \Delta G_{\text {diss- }}$ is dissociation free energy of $\mathrm{Na}_{2} \mathrm{~S}_{2} . \Delta G_{\text {diss-2 }}$ indicates formation free energy of NaS*, and $\Delta G_{B}$ indicates NaS ${ }^{*}$ formation free energy barrier. b Relationship between computed $\Delta G_{\text {diss-1 }}$ or $\Delta G_{B}$ values and measured electrodeposition capacities on the three molybdenum nitrides surfaces. $\mathbf{c}$ Atomic configurations for $\mathrm{NaS}^{\star}$ formation step on the surface of $\mathrm{Mo}_{5} \mathrm{~N}_{6}$. The gray-color, light blue, orange, and blue spheres represent Mo, N, S, and Na atoms, respectively.

dissociation, 3) two $\mathrm{NaS}^{*}$ formation following simultaneous $\mathrm{NaS}_{2}{ }^{*}$ dissociation and a Na-S bond formation. For the $\mathrm{Na}_{2} \mathrm{~S}_{2}$ dissociation step, $\mathrm{Mo}_{5} \mathrm{~N}_{6}$ exhibits an optimal free energy $\left(\Delta G_{\text {Mo5N6 diss- } 1}\right)$ value of $-0.23 \mathrm{eV}$, whilst $\mathrm{MoN}$ and $\mathrm{Mo}_{2} \mathrm{~N}$ surfaces exhibit more positive values of $\Delta G_{\mathrm{MoN}}$ diss-1 $=0.09 \mathrm{eV}$ and $\Delta G_{\mathrm{Mo} 2 \mathrm{~N} \text { diss-1 }}=0.36 \mathrm{eV}$, respectively. However, for the $\mathrm{NaS}_{2}{ }^{*}$ dissociation step, MoN shows the optimal free energy $\left(\Delta G_{\mathrm{MoN} \text { diss- }}\right)$ value of $-0.05 \mathrm{eV}$, whilst $\mathrm{Mo}_{5} \mathrm{~N}_{6}$ and $\mathrm{Mo}_{2} \mathrm{~N}$ surfaces exhibit more positive values of $\Delta G_{\text {Mo5N6 diss- } 1}=0.04 \mathrm{eV}$ and $\Delta G_{\mathrm{Mo} 2 \mathrm{~N} \text { diss- } 1}=0.39 \mathrm{eV}$, respectively. Therefore, from a thermodynamic point of view, $\mathrm{Mo}_{5} \mathrm{~N}_{6}$ and $\mathrm{MoN}$ demonstrate similar $\mathrm{Na}_{2} \mathrm{~S}$ electrodeposition activity. However, these theoretical investigations based only on adsorption energetics do not agree with the experimental observation that $\mathrm{CP} / \mathrm{Mo}_{5} \mathrm{~N}_{6}$ sample demonstrates a significantly greater $\mathrm{Na}_{2} \mathrm{~S}$ electrodeposition capacity in comparison with CP/MoN. When the kinetics of $\mathrm{NaS}^{*}$ formation step is considered (Fig. 5a and Supplementary Table 5), the $\mathrm{Mo}_{5} \mathrm{~N}_{6}$ surface exhibits a substantially lower energy barrier $\left(\Delta G_{\mathrm{B}}=0.48 \mathrm{eV}\right)$ than on $\mathrm{MoN}\left(\Delta G_{\mathrm{B}}=0.58 \mathrm{eV}\right)$ and $\mathrm{Mo}_{2} \mathrm{~N}$ $\left(\Delta G_{\mathrm{B}}=1.06 \mathrm{eV}\right) \quad$ (Fig. 5b and Supplementary Figs. 34-36). Therefore, from a kinetic viewpoint, $\mathrm{Mo}_{5} \mathrm{~N}_{6}$ demonstrates the most favorable electrodeposition efficiency amongst the three molybdenum nitride structures. With the identification of large energy barrier of $\mathrm{NaS}^{*}$ formation on the $\mathrm{Mo}_{2} \mathrm{~N}$ surface, in addition to the formation of the $\mathrm{Na}_{2} \mathrm{~S}^{*}$ state, the $\mathrm{NaS}^{*}$ formation kinetics also affect the overall deposition rate and lead to the experimentally observed activity trend (Fig. 5c). Therefore, association of the atomic reaction model (applying $\Delta G_{\text {diss-1 }}$ as a reactivity indicator) with the newly considered transition-state theory gives a qualitative confirmation of the deposition kinetics on the three molybdenum nitrides 66

To investigate the origin of fast $\mathrm{Na}_{2} \mathrm{~S}$ electrodeposition kinetics on $\mathrm{Mo}_{5} \mathrm{~N}_{6}$ from the aspect of electronic structure, spectroscopic measurements were carried out. The ex-situ NEXAFS characterizations were carried out on the three sulfur electrodes to investigate the dynamic change of the valence state of Mo in the three cathode materials. The Mo $\mathrm{L}_{3}$-edge spectra for $\mathrm{Mo}_{5} \mathrm{~N}_{6}$ (Fig. 6a) show that the valence state of Mo decreases gradually with the discharge and reaches lowest level at the discharge potential of $0.5 \mathrm{~V}$. This is consistent with the adsorption configuration from DFT results and demonstrates the strong Mo-S interaction and high $\mathrm{Na}_{2} \mathrm{~S}$ electrodeposition capacity. During the following charge, the valence state of Mo increases to the original level until the end of charge at the potential of $2.8 \mathrm{~V}$. This finding confirms the strong adsorption of sodium polysulfides and the high reversibility of $\mathrm{Mo}_{5} \mathrm{~N}_{6}$ as electrode materials. As a comparison, similar measurements were performed on electrode with MoN. The NEXAFS spectra show that valence state of Mo decreases during discharge but remains unchanged during the following charge. This indicates that although MoN exhibits strong adsorption of sodium polysulfides, the high diffusion barrier of sodium ions on MoN leads to poor reversibility of the electrode. In contrast, the $\mathrm{Mo}_{2} \mathrm{~N}$ electrode shows a nearly unchanged valence state of Mo during the whole discharge/charge. These findings confirm that $\mathrm{Na}_{2} \mathrm{~S}$ electrodeposition kinetics on the molybdenum nitrides strongly depends on the valence state and $\mathrm{d}$ electron density of Mo.

To gain further fundamental insight into the low $\mathrm{NaS}_{2}{ }^{*}$ dissociation barrier on $\mathrm{Mo}_{5} \mathrm{~N}_{6}$, charge difference analyses on the transition state configurations on three surfaces were carried out (Fig. 6b-d). On $\mathrm{MoN}$ and $\mathrm{Mo}_{2} \mathrm{~N}$ surface, the interaction between the $\mathrm{S}$ (highlighted by red-color circles in Fig. $6 \mathrm{c}-\mathrm{d}$ ) and $\mathrm{Na}$ is strong, which represents electron accumulation between the two atoms. On the $\mathrm{Mo}_{5} \mathrm{~N}_{6}$ surface, less electron accumulation is observed. This finding confirms a weaker interaction between the two atoms, which aids $\mathrm{Na}_{2} \mathrm{~S}^{*}$ dissociation with a lower 


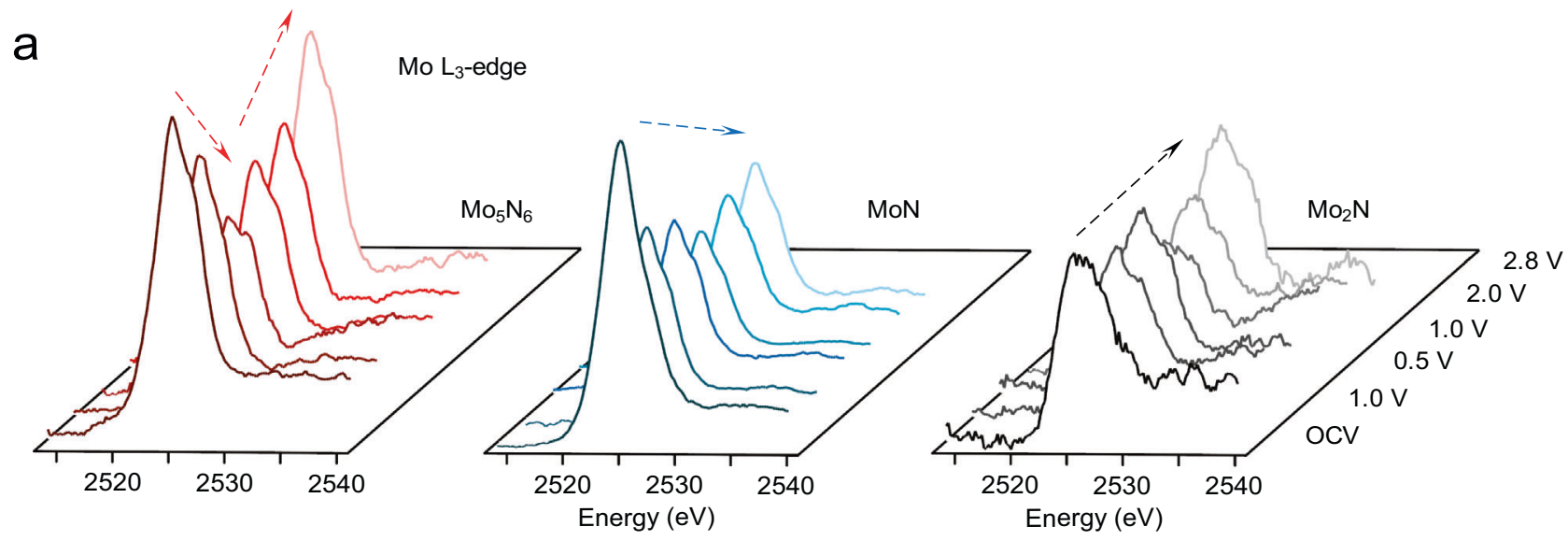

b

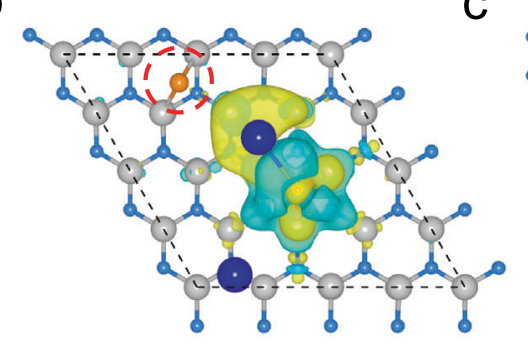

C
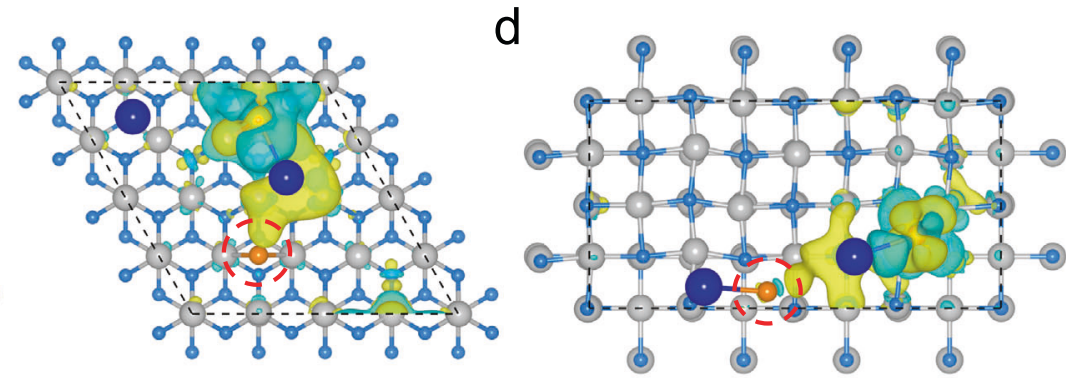

e
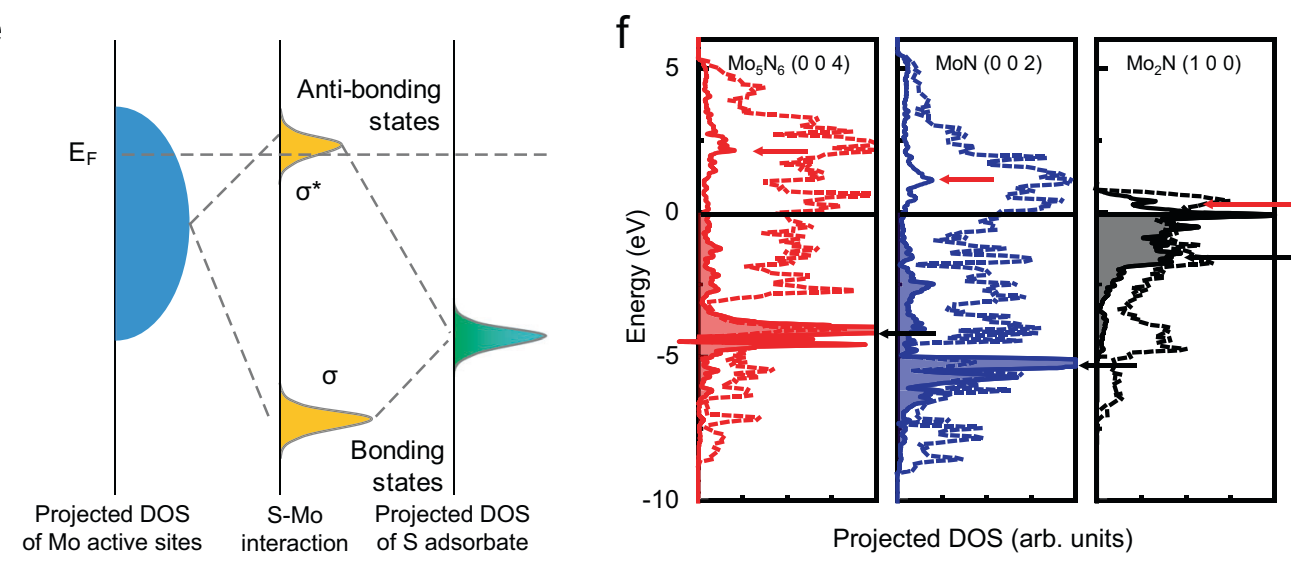

S $3 p-$ Mo $d$ antibonding
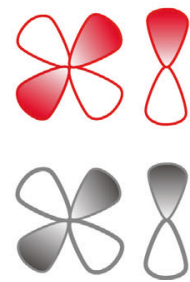

S $3 p-$ Mo $d$ bonding

Fig. 6 Analyzes of Mo electronic structure in corresponding reaction transition state. a-c Ex-situ NEXAFS for the $\mathrm{Mo}_{3}-\mathrm{edge}$ of $\mathrm{S} / \mathrm{Mo}_{5} \mathrm{~N}_{6}, \mathrm{~S} / \mathrm{MoN}$, and $\mathrm{S} / \mathrm{Mo}_{2} \mathrm{~N}$, for varying voltage during a discharge/charge cycle. b-d Charge difference analyzes from configurations of the transition states in the NaS* formation step on the three cathode materials, in which yellow-color and cyan iso-surface represent electron accumulation and electron depletion, respectively, and the iso-surface value is 0.0015 e $\AA^{-3}$. Color code is the same as for Fig. $5 c$. e Energy level diagram showing orbital hybridization for adsorption sites and adsorbate. $E_{\mathrm{F}}$ is the Fermi level of the substrate; $\sigma$ and $\sigma^{\star}$ indicate bonding and anti-bonding states, respectively. $\mathbf{f}$ Solid lines represent DOS for $\mathrm{S}$ in the red-color circles in Fig. $6 \mathrm{~b}$ - $d$. The DOS is projected onto the S $3 p$ state. Dashed lines represent surface Mo $d$-bands DOS of the three clean molybdenum nitrides surfaces.

dissociation barrier. The weaker interaction between $\mathrm{Na}$ and $\mathrm{S}$ is attributed to the strong Mo-S interaction, also demonstrated in the NEXAFS and XPS findings. The relationship between the adsorption of an adsorbate on a surface and the electronic structure of the substrate is explained by the density of states (DOS) (Fig. 6e). When a polysulfide molecule from the electrolyte is adsorbed on the molybdenum nitrides surface to form $\mathrm{Na}_{2} \mathrm{~S}_{\mathrm{n}}{ }^{*}$, the electronic states of the Mo interact with those of sulfur. Consequently, the hybridized energy levels split into two groups: one is the anti-bonding states $\left(\sigma^{*}\right)$ that normally go across the Fermi level $\left(E_{\mathrm{F}}\right)$; the other is the bonding orbital $(\sigma)$ positioned under the $E_{\mathrm{F}}$. The difference in the adsorption strength comes from the antibonding states, that is, with a higher location of the $E_{\mathrm{F}}$ of the molybdenum nitrides, the antibonding states move to lower occupancy. This leads to a stronger interaction between $\mathrm{Na}_{2} \mathrm{~S}_{\mathrm{n}}{ }^{*}$ and the molybdenum nitrides surface, and vice versa ${ }^{67}$. In this work, the results of the DOS computations are consistent with the scheme, Fig. 6f. The low DOS peaks of the S 3p-Mo $d$ antibonding orbitals (indicated by arrows) cause weak adsorption of $\mathrm{S}$ on $\mathrm{MoN}$ and $\mathrm{Mo}_{2} \mathrm{~N}$. More importantly, the position of antibonding orbital is decided by the $d$-band position of Mo on the molybdenum nitrides; the $d$-band centers for the Mo atoms on the $\mathrm{Mo}_{5} \mathrm{~N}_{6}, \mathrm{MoN}$, and $\mathrm{Mo}_{2} \mathrm{~N}$ are $-0.41,-1.56$, and $-2.41 \mathrm{eV}$, respectively. This is the same order as for the S-Mo antibonding 
peaks on the three surfaces. Therefore, the $d$-band position shows similar trends with the adsorption strength as is shown in Supplementary Fig. 37. The $d$-band center (applying as a descriptor) can be correlated with the $\mathrm{Na}_{2} \mathrm{~S}_{2}{ }^{*}$ dissociation energy as the underlying mechanism of the better electrodeposition reactivity of $\mathrm{Mo}_{5} \mathrm{~N}_{6}$ in sulfur cathodes.

Using sodium-sulfur chemistry as an example, we correlated the $\mathrm{Na}_{2} \mathrm{~S}$ electrodeposition reactivity on a $\mathrm{Mo}_{5} \mathrm{~N}_{6}$ electrocatalyst with its reaction energetics and inherent electronic structure. By identifying the significant influence of $\mathrm{Na}_{2} \mathrm{~S}_{2}$ dissociation on the overall SRR reactivity of various molybdenum nitrides surfaces, we elucidated the mechanism of metal sulfides electrodeposition through the association of atomic reaction model with the transition-state theory. The combination of experimental data and theoretical computations demonstrates that $\mathrm{Mo}_{5} \mathrm{~N}_{6}$ with favorable $d$-band position delivers significantly high $\mathrm{Na}_{2} \mathrm{~S}$ electrodeposition reactivity and performance in Na-S battery. This advance in mechanistic understanding of metal sulfides electrodeposition will underpin rational design of efficient $\mathrm{M}-\mathrm{S}$ batteries. Application has resulted in significant performance of an $\mathrm{RT} \mathrm{Na}-\mathrm{S}$ battery. Findings will be of immediate interest and practical benefit to a wide range of researchers in the rational design of electrode materials for accelerated applications in sustainable energy-storage and conversion.

\section{Methods}

Preparation of molybdenum nitrides. Mo powder $(<150 \mu \mathrm{m}, 99.99 \%$ trace metals basis) was purchased from Sigma-Aldrich without further purification. The $2 \mathrm{D}$ $\mathrm{Mo}_{5} \mathrm{~N}_{6}$ nanosheets were synthesized through a Ni-induced salt-templated method as previously reported: $0.4 \mathrm{~g}$ of Mo powder was dispersed in $40 \mathrm{~mL}$ of ethanol with magnetic stirring for $10 \mathrm{~min}^{28}$. $1.2 \mathrm{~mL}$ of $\mathrm{H}_{2} \mathrm{O}_{2}$ (30 wt\%) solution was injected dropwise into the suspension. Following stirring for $12 \mathrm{~h}$ at room temperature, the solution turned into a dark-blue color. Separately, $10 \mathrm{mg}$ of $\mathrm{Ni}\left(\mathrm{OCOCH}_{3}\right)_{2} \cdot 4 \mathrm{H}_{2} \mathrm{O}$ was dissolved in $10 \mathrm{~mL}$ of ethanol and mixed with the dark-blue suspension to form the precursor. The precursor solution was mixed with $640 \mathrm{~g}$ of $\mathrm{NaCl}$ powder and dried at $50{ }^{\circ} \mathrm{C}$ with continuous hand-stirring. The mixture was annealed at $750{ }^{\circ} \mathrm{C}$ for $5 \mathrm{~h}$ at a heating rate of $1{ }^{\circ} \mathrm{C} \mathrm{min}-1$ under a $5 \% \mathrm{NH}_{3} / \mathrm{Ar}$ atmosphere. The product was washed with deionized water and dilute hydrochloric acid several times to remove the $\mathrm{NaCl}$ template and $\mathrm{Ni}$ nanoparticles before being dried using vacuum filtration. The $2 \mathrm{D} \mathrm{MoN}$ nanosheets were synthesized without addition of $\mathrm{Ni}$. The Mo precursor was mixed with $640 \mathrm{~g}$ of $\mathrm{NaCl}$ and annealed at $750{ }^{\circ} \mathrm{C}$ for $5 \mathrm{~h}$. The final product was obtained by removing $\mathrm{NaCl}$ using deionized water and vacuum filtration. The $\mathrm{Mo}_{2} \mathrm{~N}$ nanoparticles were produced by annealing $\mathrm{Mo}$ powder under $\mathrm{NH}_{3}$ atmosphere. Fifty milligram of Mo powder was put into a porcelain boat uniformly. The powder was annealed at $650{ }^{\circ} \mathrm{C}$ for $5 \mathrm{~h}$ at the ramp rate of $1{ }^{\circ} \mathrm{C} \mathrm{min}^{-1}$ under $5 \% \mathrm{NH}_{3} / \mathrm{Ar}$ atmosphere.

Materials characterization. The morphology and structure of samples was characterized by SEM (FEI Quanta 450). HAADF-STEM images were recorded at $200 \mathrm{kV}$ (Talos F200X). XRD data were recorded on a Rigaku MiniFlex 600 X-Ray Diffractometer. Sulfur content of the active material was determined by TGA (METTLER TOLEDO TGA/DSC 2) under $\mathrm{N}_{2}$. In-situ synchrotron XRD (with wavelength $\lambda=0.6888 \AA$ ) and NEXAFS data were detected on the powder diffraction and the soft X-ray spectroscopy beamline in the Australian Synchrotron, Clayton, Victoria.

Electrochemical characterization. For the battery performance measurement, active sulfur material containing elemental sulfur and conductive carbon (Ketjen Balck) with mass ratio of 2:1 was well-mixed and sealed in a quartz ampoule and thermally treated at $300{ }^{\circ} \mathrm{C}$ for $2 \mathrm{~h}$ under a $\mathrm{N}_{2}$ atmosphere. $5 \mathrm{wt} \% \mathrm{Mo}_{\mathrm{x}} \mathrm{N}_{\mathrm{y}}$ was used as the additive in the slurry together with $80 \mathrm{wt} \%$ of active material, $5 \mathrm{wt} \%$ of conductive carbon and $10 \mathrm{wt} \% \mathrm{~N}$-lauryl acrylate (LA133, purchased from Chengdu Yindile Power Supply Technology). For comparison, a pure S/C electrode was prepared with a slurry containing $80 \mathrm{wt} \%$ active material, $10 \mathrm{wt} \%$ conductive carbon and $10 \mathrm{wt} \% \mathrm{~N}$-lauryl acrylate. The slurry mixture was cast on aluminumfoil and dried at $50{ }^{\circ} \mathrm{C}$ overnight to fabricate the sulfur electrodes with average thickness of $\sim 20 \mu \mathrm{m}$. The 2032-type coin cells were assembled using glass-fiber as the separator and $\mathrm{Na}$ metal with average thickness of $\sim 500 \mu \mathrm{m}$ and purity of $99.9 \%$ as the anode. The electrolyte consisted of $1.0 \mathrm{M} \mathrm{NaClO}_{4}$ in ethylene carbonate (EC)/propylene carbonate (PC) with a volume ratio of $1: 1$ and $5 \mathrm{wt} \%$ fluoroethylene carbonate (FEC) additive. The volume of electrolyte injected into the coin cells was controlled to $15 \mu \mathrm{L}$ in total. The areal active material loading in the cathode for rating and cycling performance was $\sim 1.2 \mathrm{mg} \mathrm{cm}^{-2}$. The area of the sulfur electrodes are $\sim 1.13 \mathrm{~cm}^{-2}$. The galvanostatic charge/discharge measurements were performed under $30^{\circ} \mathrm{C}$ in a constant temperature oven using NEWARE and LAND CT2001A battery testers. The capacities were calculated based on the mass of the elemental sulfur. For all the cycling and rating tests, a $0.1 \mathrm{C}$ low-rate cycle were adopted to activate the redox reactivity of the elemental sulfur. Electrochemical impedance spectroscopy tests were performed at specific voltages in the frequency range $1 \mathrm{MHz}$ to $0.01 \mathrm{~Hz}$ with an amplitude of $5 \mathrm{mV}$ after resting for $10 \mathrm{~min}$. A thermal test chamber (MSK-TE906) was used to control the temperature during the EIS testing. To stabilize voltage, the battery was discharged to the particular potential and held at that potential until the output current remained constant. For in-situ synchrotron XRD measurements, the in-situ cells were similar to the coin cells for electrochemical performance testing and were discharged to $1.5 \mathrm{~V}$ under $0.1 \mathrm{C}$ prior to measurement of $\mathrm{Na}_{2} \mathrm{~S}$ electrodeposition. To guarantee that the X-ray beams could penetrate the whole cell, three holes with $4 \mathrm{~mm}$ diameter were punched in the center of the negative, the positive battery shells and the spacer. Kapton film was used to cover the holes in the negative and positive caps, and glue was used for sealing. The assembly of the in-situ cells was the same as that for the cells for the electrochemical tests. For the ex-situ measurements, the cells with test electrodes were discharged or charged to the specific voltage under $0.1 \mathrm{C}$, then were dissembled in a glove box. The test electrodes were sealed in a sample-holder within the glove box to transport the electrode samples.

$\mathbf{N a}_{2} \mathbf{S}$ electrodeposition experiments. The $\mathrm{Na}_{2} \mathrm{~S}$ ( $>97.0 \%$ ), sulfur powder (reagent grade, 100 mesh particle size), tetraglyme (>99\%) and glass fiber separator (Whatman ${ }^{\circledR}$ glass microfiber filter, Grade GF/F) were purchased from SigmaAldrich Australia. The $\mathrm{Na}_{2} \mathrm{~S}$ powder was stored in glove box. The carbon papers (CF) were purchased from Shanghai Hesen Electronics Co. Ltd. (HCP010N). The original $\mathrm{Li}_{2} \mathrm{~S}$ electrodeposition tests are referred to for the $\mathrm{Na}_{2} \mathrm{~S}$ electrodeposition tests ${ }^{11}$. The $\mathrm{Na}_{2} \mathrm{~S}$ electrodeposition from soluble polysulfides was studied by potentiostatic deposition in $\mathrm{Na}_{2} \mathrm{~S}_{4}$ tetraglyme solution on the CF current collectors The $\mathrm{Na}_{2} \mathrm{~S}_{4}$ tetraglyme solution was applied to compare the delicate kinetical differences for different samples with corresponding electrodeposition films and capacities. The test was conducted in a similar coin cell as for the electrochemical performance tests. The $\mathrm{Na}_{2} \mathrm{~S}_{4}$ in tetraglyme solution added to the $\mathrm{Mo}_{\mathrm{x}} \mathrm{N}_{\mathrm{y}}$ on CF was the only source of sulfur active material. The $0.1 \mathrm{M} \mathrm{Na}_{2} \mathrm{~S}_{4}$ solution was prepared by dissolving and mixing stoichiometric amounts of $\mathrm{Na}_{2} \mathrm{~S}$ and sulfur in tetraglyme solvent at room temperature for $10 \mathrm{~h}$. CF papers were punched into disks with a diameter of $12 \mathrm{~mm}$ and about $0.40 \mathrm{mg}$ of $\mathrm{Mo}_{5} \mathrm{~N}_{6}, \mathrm{MoN}$, and $\mathrm{Mo}_{2} \mathrm{~N}$ powders were separately dispersed on $\mathrm{CF}$ papers using pure ethanol as solvent. $25 \mu \mathrm{L} \mathrm{Na} \mathrm{S}_{4}$ was dropped onto the as-prepared current collectors as cathode. Sodium-foil was employed at the counter electrode, which was separated with cathode by glassfiber membrane and dropped with $15 \mu \mathrm{L}$ electrolyte. The cells were galvanostatically discharged to $1.0 \mathrm{~V}$ at a constant specific current of $\mathrm{C} / 24$, and kept potentiostatically at $0.5 \mathrm{~V}$ for $\mathrm{Na}_{2} \mathrm{~S}$ to nucleate and grow until the current dropped below $10^{-5} \mathrm{~A}$.

Computational methods. DFT computations were carried out using the Vienna Ab-initio Simulation Package (VASP) ${ }^{68,69}$. The exchange-correlation interaction was described by generalized gradient approximation (GGA) with the Perdew-Burke-Ernzerhof (PBE) functional ${ }^{70}$. The DFT-TS method of Grimme was employed to treat the VDW interaction ${ }^{71}$. All computations were carried out using a plane wave kinetic energy cut-off of $600 \mathrm{eV}$. All structures in the computations were spin-polarized and relaxed until the convergence tolerance of force on each atom was less than $0.01 \mathrm{eV}$. The energy convergence criteria were set to $10^{-4} \mathrm{eV}$ for self-consistent computations with a Gamma centered $2 \times 2 \times 1$ K-points. All periodic slabs had a vacuum spacing of at least $15 \AA$. Denser $10 \times 10$ $\times 1 \mathrm{~K}$-points were used for the density of states (DOS) computations. All periodic slabs had a vacuum spacing of at least $15 \AA$. The structural model for $\mathrm{Mo}_{5} \mathrm{~N}_{6}\left(\begin{array}{lll}0 & 0 & 4\end{array}\right)$ facet contained five Mo-N layers with a supercell size of $a=b=11.44 \AA$, $c=20.60 \AA, \alpha=\beta=90^{\circ}$, and $\gamma=120^{\circ}$. The structural model for MoN $\left(\begin{array}{lll}0 & 0 & 2\end{array}\right)$ facet contains five Mo-N layers with a supercell size of $a=b=11.36 \AA, c=20.70 \AA$, $\alpha=\beta=90^{\circ}$ and $\gamma=120^{\circ}$ while the $\mathrm{Mo}_{2} \mathrm{~N}\left(\begin{array}{lll}1 & 0 & 0\end{array}\right)$ facet consisted of five Mo-N layers with $a=b=8.33 \AA, c=23.33 \AA, \alpha=\beta=\gamma=90^{\circ}$. In computations the three bottom layers were kept fixed, all other atoms were allowed to relax. $\mathrm{Na}_{2} \mathrm{~S}_{\mathrm{n}}$ ( $n=1-5)$ adsorption energies $\Delta E$ for each configuration were computed from:

$$
\Delta E=E_{\text {total }}-E_{\mathrm{Na} 2 \mathrm{Sn}}-E_{\mathrm{s}}
$$

where $E_{\text {total }}, E_{\mathrm{Na} 2 \mathrm{Sn}}$, and $E_{\mathrm{s}}$ are, respectively, the energies for the whole system, $\mathrm{Na}_{2} \mathrm{~S}_{\mathrm{n}}$ and substrate.

Free energy diagram computation. Based on the experimentally obtained ratedetermining step, the solid-solid conversion from $\mathrm{Na}_{2} \mathrm{~S}_{2}$ to $\mathrm{Na}_{2} \mathrm{~S}$ was proposed as three elementary steps, namely:

$$
\begin{gathered}
{ }^{*} \mathrm{Na}_{2} \mathrm{~S}_{2}+2 \mathrm{Na}^{+}+2 \mathrm{e}^{-} \\
* \mathrm{NaS}_{2}+{ }^{*} \mathrm{Na}+2 \mathrm{Na}^{+}+2 \mathrm{e}^{-} \\
2 * \mathrm{NaS}+2 \mathrm{Na}^{+}+2 \mathrm{e}^{-}
\end{gathered}
$$

in which $*$ indicates a reaction site. The free energies for the three steps are $\Delta G_{\text {diss-1 }}$ 
and $\Delta G_{\text {diss-2 }}$, respectively, and can be computed from:

$$
\begin{aligned}
\Delta \mathrm{G}_{\text {diss }-1} & =\mathrm{G}\left({ }^{*} \mathrm{NaS}_{2}+{ }^{*} \mathrm{Na}\right)-\mathrm{G}\left({ }^{*} \mathrm{Na}_{2} \mathrm{~S}_{2}\right) \\
\Delta \mathrm{G}_{\text {diss }-2} & =\mathrm{G}\left(2^{*} \mathrm{NaS}\right)-\mathrm{G}\left({ }^{*} \mathrm{NaS}_{2}+{ }^{*} \mathrm{Na}\right)
\end{aligned}
$$

in which

$$
G=E+E_{\mathrm{ZPE}}-\mathrm{TS}
$$

and where zero point energy corrections $\left(E_{\mathrm{ZPE}}\right)$ and entropic contributions (TS; $T$ was set to be $273.15 \mathrm{~K}$ ). The free energy of the $\Delta G_{\text {diss-1 }}$ and $\Delta G_{\text {diss-2 }}$ were computed as:

$$
\Delta G=\Delta E+\Delta E_{\mathrm{ZPE}}-T \Delta S,
$$

where $\Delta E_{\mathrm{ZPE}}$ and $\Delta S$ are the binding energy, zero point energy change and entropy change, respectively. In this work the values of $\Delta E_{\mathrm{ZPE}}$ and $\Delta S$ on the specific molybdenum nitrides surfaces were determined by vibrational frequency computation. Note that the exploration of active sites on the specific surface was conducted and chosen according to the most energetically stable adsorption site.

$\mathrm{Na}_{2} \mathbf{S}_{\mathbf{2}}$ dissociation barrier computation. Following identification of the initial and final states for $\mathrm{Na}_{2} \mathrm{~S}_{2}$ dissociation step on the three molybdenum nitrides surfaces, the energy barrier was located via searching for transition states by climbing image nudged-elastic band (CI-NEB) method implemented in VASP ${ }^{21}$ The transition states were obtained by relaxing the force below $0.05 \mathrm{eV} \AA^{-1}$. The located transition states were confirmed by frequency analysis. The $d$-band center $\left(\varepsilon_{\mathrm{d}}\right)$ was determined as the weighted DOS center of $d$-band as:

$$
\varepsilon_{\mathrm{d}}=\sum_{\mathrm{i}} \varepsilon_{\mathrm{i}} \mathrm{r}_{\mathrm{i}} / \sum_{\mathrm{i}} \varepsilon_{\mathrm{i}}
$$

where $r_{\mathrm{i}}$ is the DOS at energy $\varepsilon_{\mathrm{i}}$

Reporting summary. Further information on research design is available in the Nature Research Reporting Summary linked to this article.

\section{Data availability}

Data that support findings from this study are available from the corresponding author on request.

Received: 26 March 2021; Accepted: 26 November 2021; Published online: 10 December 2021

\section{References}

1. Ji, X., Lee, K. T. \& Nazar, L. F. A highly ordered nanostructured carbon-sulphur cathode for lithium-sulphur batteries. Nat. Mater. 8, 500-506 (2009).

2. Park, C.-W., Ahn, J.-H., Ryu, H.-S., Kim, K.-W. \& Ahn, H.-J. Roomtemperature solid-state sodium/ sulfur battery. Electrochem Solid State Lett. 9, A123-A125 (2006).

3. Zhao, Q., Hu, Y., Zhang, K. \& Chen, J. Potassium-sulfur batteries: a new member of room-temperature rechargeable metal-sulfur batteries. Inorg. Chem. 53, 9000-9005 (2014).

4. Kim, H. S. et al. Structure and compatibility of a magnesium electrolyte with a sulphur cathode. Nat. Commun. 2, 427 (2011)

5. Wang, Y.-X. et al. Achieving high-performance room-temperature sodiumsulfur batteries with S@interconnected mesoporous carbon hollow nanospheres. J. Am. Chem. Soc. 138, 16576-16579 (2016).

6. Zhao, C. et al. A high-energy and long-cycling lithium-sulfur pouch cell via a macroporous catalytic cathode with double-end binding sites. Nat. Nanotechnol. 16, 166-173 (2020).

7. Peng, L. et al. A fundamental look at electrocatalytic sulfur reduction reaction. Nat. Catal. 3, 762-770 (2020).

8. Zhou, L., Danilov, D. L., Eichel, R.-A. \& Notten, P. H. L. Host materials anchoring polysulfides in Li-S batteries reviewed. Adv. Energy Mater. 11, 2001304 (2021).

9. Zhao, M. et al. Lithium-sulfur batteries under lean electrolyte conditions: Challenges and opportunities. Angew. Chem. Ed. 59, 12636-12652 (2020)

10. Zhang, L. et al. Design rules of heteroatom-doped graphene to achieve high performance lithium-sulfur batteries: both strong anchoring and catalysing based on first principles calculation. J. Colloid Interface Sci. 529, 426-431 (2018).

11. Fan, F. Y., Carter, W. C. \& Chiang, Y. M. Mechanism and kinetics of $\mathrm{Li}_{2} \mathrm{~S}$ precipitation in lithium-sulfur batteries. Adv. Mater. 27, 5203-5209 (2015)

12. Liu, D. et al. Catalytic effects in lithium-sulfur batteries: promoted sulfur transformation and reduced shuttle effect. Adv. Sci. 5, 1700270 (2018).
13. Yang, $\mathrm{X}$. et al. Promoting the transformation of $\mathrm{Li}_{2} \mathrm{~S}_{2}$ to $\mathrm{Li}_{2} \mathrm{~S}$ : significantly increasing utilization of active materials for high-sulfur-loading Li-S batteries. Adv. Mater. 31, 1901220 (2019).

14. He, J. \& Manthiram, A. A review on the status and challenges of electrocatalysts in lithium-sulfur batteries. Energy Storage Mater. 20, 55-70 (2019).

15. Ye, C. et al. Unveiling the advances of $2 \mathrm{D}$ materials for $\mathrm{Li} / \mathrm{Na}-\mathrm{S}$ batteries experimentally and theoretically. Matter 2, 323-344 (2020).

16. Song, Y. et al. Rationalizing electrocatalysis of Li-S chemistry by mediator design: progress and prospects. Adv. Energy Mater. 10, 1901075 (2020).

17. Lim, W.-G., Kim, S., Jo, C. \& Lee, J. A comprehensive review of materials with catalytic effects in Li-S batteries: enhanced redox kinetics. Angew. Chem. Ed. 58, 18746-18757 (2019).

18. Pampel, J., Dörfler, S., Althues, H. \& Kaskel, S. Designing room temperature sodium sulfur batteries with long cycle-life at pouch cell level. Energy Storage Mater. 21, 41-49 (2019).

19. Yan, Y., Cheng, C., Zhang, L., Li, Y. \& Lu, J. Deciphering the reaction mechanism of lithium-sulfur batteries by in situ/operando synchrotron-based characterization techniques. Adv. Energy Mater. 9, 1900148 (2019).

20. Gu, Q., Kimpton, J. A., Brand, H. E., Wang, Z. \& Chou, S. Solving key challenges in battery research using in situ synchrotron and neutron techniques. Adv. Energy Mater. 7, 1602831 (2017).

21. Li, S. et al. High performance room temperature sodium-sulfur battery by eutectic acceleration in tellurium-doped sulfurized polyacrylonitrile. ACS Appl Energy Mater. 2, 2956-2964 (2019).

22. Kumar, A., Ghosh, A., Forsyth, M., MacFarlane, D. R. \& Mitra, S. Free-radical catalysis and enhancement of the redox kinetics for room-temperature sodium-sulfur batteries. ACS Energy Lett. 5, 2112-2121 (2020).

23. Xu, X. et al. A room-temperature sodium-sulfur battery with high capacity and stable cycling performance. Nat. Commun. 9, 3870 (2018)

24. Wang, Y. et al. Revitalising sodium-sulfur batteries for non-high-temperature operation: a crucial review. Energy Environ. Sci. 13, 3848-3879 (2020).

25. Chen, X., Hou, T., Persson, K. A. \& Zhang, Q. Combining theory and experiment in lithium-sulfur batteries: current progress and future perspectives. Mater. Today 22, 142-158 (2019).

26. Li, P. et al. Chemical immobilization and conversion of active polysulfides directly by copper current collector: a new approach to enabling stable roomtemperature Li-S and Na-S batteries. Adv. Energy Mater. 8, 1800624 (2018).

27. Zhang, S., Yao, Y. \& Yu, Y. Frontiers for room-temperature sodium-sulfur batteries. ACS Energy Lett. 6, 529-536 (2021).

28. Jin, H. et al. Single-crystal nitrogen-rich two-dimensional $\mathrm{Mo}_{5} \mathrm{~N}_{6}$ nanosheets for efficient and stable seawater splitting. ACS Nano 12, 12761-12769 (2018).

29. Ye, C. et al. Electron-state confinement of polysulfides for highly stable sodium-sulfur batteries. Adv. Mater. 32, 1907557 (2020).

30. Jin, H. et al. Constructing tunable dual active sites on two-dimensional $\mathrm{C}_{3} \mathrm{~N}_{4} @ \mathrm{MoN}$ hybrid for electrocatalytic hydrogen evolution. Nano Energy 53, 690-697 (2018)

31. Lede, E. J., Requejo, F. G., Pawelec, B. \& Fierro, J. L. G. XANES Mo L-Edges and XPS study of Mo loaded in HY zeolite. J. Phys. Chem. B 106, 7824-7831 (2002).

32. Wei, Z. B. Z., Grange, P. \& Delmon, B. XPS and XRD studies of fresh and sulfided $\mathrm{Mo}_{2} \mathrm{~N}$. Appl Surf. Sci. 135, 107-114 (1998).

33. Wei, S. et al. A stable room-temperature sodium-sulfur battery. Nat Commun. 7, 11722 (2016)

34. Zhang, S. et al. Altering the electrochemical pathway of sulfur chemistry with oxygen for high energy density and low shuttling in a Na/S battery. ACS Energy Lett. 5, 1070-1076 (2020).

35. Zhang, B. et al. Long-life room-temperature sodium-sulfur batteries by virtue of transition metal nanocluster-sulfur interactions. Angew. Chem. 131, 1498-1502 (2018).

36. Vijaya Kumar Saroja, A. P., Muthusamy, K. \& Sundara, R. Strong surface bonding of polysulfides by teflonized carbon matrix for enhanced performance in room temperature sodium-sulfur battery. Adv. Mater. Interfaces 6, 1801873 (2019).

37. Zhang, B.-W. et al. Atomic cobalt as an efficient electrocatalyst in sulfur cathodes for superior room-temperature sodium-sulfur batteries. Nat. Commun. 9, 4082 (2018).

38. Wang, C. et al. Frogspawn-coral-like hollow sodium sulfide nanostructured cathode for high-rate performance sodium-sulfur batteries. Adv. Energy Mater. 9, 1803251 (2018)

39. Xia, G. et al. Carbon hollow nanobubbles on porous carbon nanofibers: an ideal host for high-performance sodium-sulfur batteries and hydrogen storage. Energy Storage Mater. 14, 314-323 (2018).

40. Zhang, L. et al. Self-assembling hollow carbon nanobeads into doubleshell microspheres as a hierarchical sulfur host for sustainable roomtemperature sodium-sulfur batteries. ACS Appl Mater. Interfaces 10, 20422-20428 (2018) 
41. Lu, Q. et al. Freestanding carbon fiber cloth/sulfur composites for flexible room-temperature sodium-sulfur batteries. Energy Storage Mater. 8, 77-84 (2017).

42. Carter, R. et al. A sugar-derived room-temperature sodium sulfur battery with long term cycling stability. Nano Lett. 17, 1863-1869 (2017).

43. Chen, Y.-M. et al. A nitrogen doped carbonized metal-organic framework for high stability room temperature sodium-sulfur batteries. J. Mater. Chem. A 4, 12471-12478 (2016).

44. Fan, L., Ma, R., Yang, Y., Chen, S. \& Lu, B. Covalent sulfur for advanced room temperature sodium-sulfur batteries. Nano Energy 28, 304-310 (2016).

45. Bauer, I., Kohl, M., Althues, H. \& Kaskel, S. Shuttle suppression in room temperature sodium-sulfur batteries using ion selective polymer membranes. Chem. Commun. 50, 3208-3210 (2014).

46. Tao, X. et al. Balancing surface adsorption and diffusion of lithiumpolysulfides on nonconductive oxides for lithium-sulfur battery design. Nat. Commun. 7, 11203 (2016).

47. Wang, Y.-X. et al. Room-temperature sodium-sulfur batteries: a comprehensive review on research progress and cell chemistry. Adv. Energy Mater. 7, 1602829 (2017).

48. Hao, J. et al. Heterostructure manipulation via in situ localized phase transformation for high-rate and highly durable lithium ion storage. ACS Nano 12, 10430-10438 (2018).

49. Zhou, G. et al. Catalytic oxidation of $\mathrm{Li}_{2} \mathrm{~S}$ on the surface of metal sulfides for $\mathrm{Li}$ -S batteries. Proc. Natl Acad. Sci. USA 114, 840-845 (2017).

50. Chao, D. et al. C-Plasma of hierarchical graphene survives SnS bundles for ultrastable and high volumetric Na-ion storage. Adv. Mater. 30, 1804833 (2018).

51. Sun, G.-D., Zhang, G.-H. \& Chou, K.-C. Synthesis of molybdenum nitrides nanosheets by nitriding $2 \mathrm{H}-\mathrm{MoS}_{2}$ with ammonia. J. Am. Ceram. Soc. 101, 2796-2808 (2018).

52. Zhao, J. et al. Insights into the mechanism of ammonia decomposition on molybdenum nitrides based on DFT studies. J. Phys. Chem. C 123, 554-564 (2019).

53. Altarawneh, M. et al. Conversion of $\mathrm{NO}$ into $\mathrm{N}_{2}$ over $\gamma-\mathrm{Mo}_{2} \mathrm{~N}$. J. Phys. Chem. C. 120, 22270-22280 (2016).

54. $\mathrm{Xu}$, J. et al. Promoting lithium polysulfide/sulfide redox kinetics by the catalyzing of zinc sulfide for high performance lithium-sulfur battery. Nano Energy 51, 73-82 (2018).

55. Krewer, U. et al. Review-dynamic models of Li-ion batteries for diagnosis and operation: a review and perspective. J. Electrochem. Soc. $\mathbf{1 6 5}$ A3656-A3673 (2018).

56. Tan, G. et al. Burning lithium in $\mathrm{CS}_{2}$ for high-performing compact $\mathrm{Li}_{2}$ S-graphene nanocapsules for Li-S batteries. Nat. Energy 2, 17090 (2017).

57. Zhang, B.-W. et al. Long-life room-temperature sodium-sulfur batteries by virtue of transition-metal-nanocluster-sulfur interactions. Angew. Chem. Ed. 58, 1484-1488 (2019).

58. Xie, J. et al. Implanting atomic cobalt within mesoporous carbon toward highly stable lithium-sulfur batteries. Adv. Mater. 31, 1903813 (2019).

59. Zhang, G., Zhang, Z.-W., Peng, H.-J., Huang, J.-Q. \& Zhang, Q. A toolbox for lithium-sulfur battery research: methods and protocols. Small Methods 1, 1700134-1700165 (2017).

60. Zhao, M. et al. Redox comediation with organopolysulfides in Working lithium-sulfur batteries. Chem 6, 3297-3311 (2020).

61. Yu, X. \& Manthiram, A. Capacity enhancement and discharge mechanisms of room-temperature sodium-sulfur batteries. ChemElectroChem 1, 1275-1280 (2014).

62. Qiu, L. \& Xu, G. Peak overlaps and corresponding solutions in the X-ray photoelectron spectroscopic study of hydrodesulfurization catalysts. Appl Surf. Sci. 256, 3413-3417 (2010).

63. Ma, D. et al. New strategy for polysulfide protection based on atomic layer deposition of $\mathrm{TiO}_{2}$ onto ferroelectric-encapsulated cathode: toward ultrastable free-standing room temperature sodium-sulfur batteries. Adv. Funct. Mater. 28, 1705537 (2018).

64. Chen, X. et al. An analogous periodic law for strong anchoring of polysulfides on polar hosts in lithium sulfur batteries: S-or Li-binding on first-row transition-metal sulfides? ACS Energy Lett. 2, 795-801 (2017).

65. Pang, Q., Liang, X., Kwok, C. Y. \& Nazar, L. F. Advances in lithium-sulfur batteries based on multifunctional cathodes and electrolytes. Nat. Energy 1, 16132 (2016).
66. Bligaard, T. et al. The Brønsted-Evans-Polanyi relation and the volcano curve in heterogeneous catalysis. J. Catal. 224, 206-217 (2004).

67. Jiao, Y., Zheng, Y., Davey, K. \& Qiao, S.-Z. Activity origin and catalyst design principles for electrocatalytic hydrogen evolution on heteroatom-doped graphene. Nat. Energy 1, 16130-16138 (2016).

68. Kresse, G. \& Furthmüller, J. Efficient iterative schemes for ab initio totalenergy calculations using a plane-wave basis set. Phys. Rev. B 54, 11169-11186 (1996).

69. Kresse, G. Efficiency of ab-initio total energy calculations for metals and semiconductors using a plane-wave basis set. Comput. Mater. Sci. 6, 15 (1996).

70. Perdew, J. P. Generalized gradient approximation made simple. Phys. Rev. Lett. 77, 3865-3868 (1996).

71. Tkatchenko, A. \& Scheffler, M. Accurate molecular van Der Waals interactions from ground-state electron density and free-atom reference data. Phys. Rev. Lett. 102, 073005 (2009).

\section{Acknowledgements}

This work was supported financially by the Australian Research Council (ARC) through Discovery Project FL170100154. DFT computations were undertaken with the assistance of resources and services from the National Computational Infrastructure (NCI) and Phoenix High Performance Computing, which are supported by the Australian Government and The University of Adelaide. The authors thank Dr Bruce Cowie at the Australian Synchrotron, Clayton, Victoria for assistance with NEXAFS.

\section{Author contributions}

S.-Z.Q. conceived and supervised the research; C.Y. designed and carried out the experiments; H.J. helped to fabricate materials; J.S. conducted NEXAFS and XPS tests; H.L. helped to analyze the experimental data and the sulfur cathode design; Y.J. provided guidance for the DFT computations; Q.G. helped with the in-situ synchrotron XRD tests; S.-Z.Q., K.D., and H.W. revised the manuscript. All authors discussed results and commented on the manuscript.

\section{Competing interests}

The authors declare no competing interests.

\section{Additional information}

Supplementary information The online version contains supplementary material available at https://doi.org/10.1038/s41467-021-27551-7.

Correspondence and requests for materials should be addressed to Haihui Wang or ShiZhang Qiao.

Peer review information Nature Communications thanks Sagar Mitra, Francesco Nobili, Sathiyaraj Kandhasamy and the other, anonymous, reviewer(s) for their contribution to the peer review of this work.

Reprints and permission information is available at http://www.nature.com/reprints

Publisher's note Springer Nature remains neutral with regard to jurisdictional claims in published maps and institutional affiliations.

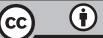

Open Access This article is licensed under a Creative Commons Attribution 4.0 International License, which permits use, sharing, adaptation, distribution and reproduction in any medium or format, as long as you give appropriate credit to the original author(s) and the source, provide a link to the Creative Commons license, and indicate if changes were made. The images or other third party material in this article are included in the article's Creative Commons license, unless indicated otherwise in a credit line to the material. If material is not included in the article's Creative Commons license and your intended use is not permitted by statutory regulation or exceeds the permitted use, you will need to obtain permission directly from the copyright holder. To view a copy of this license, visit http://creativecommons.org/ licenses/by/4.0/.

(C) The Author(s) 2021 